\title{
Van der Waals epitaxy of continuous thin films of 2D materials using atomic layer deposition in low temperature and low vacuum conditions
}

\section{Mattinen, Miika}

2020-01

Mattinen , M , King , P J , Popov , G, Hämäläinen , J , Heikkilä , M J , Leskelä , M \& Ritala , M 2020 , ' Van der Waals epitaxy of continuous thin films of 2D materials using atomic layer deposition in low temperature and low vacuum conditions ' , 2D Materials , vol. 7 , no. 1 , 011003 . https://doi.org/10.1088/2053-1583/ab4c09

http://hdl.handle.net/10138/320758

https://doi.org/10.1088/2053-1583/ab4c09

cc_by_nc_nd

acceptedVersion

Downloaded from Helda, University of Helsinki institutional repository.

This is an electronic reprint of the original article.

This reprint may differ from the original in pagination and typographic detail.

Please cite the original version. 


\title{
van der Waals Epitaxy of Continuous Thin Films of 2D
}

\section{Materials Using Atomic Layer Deposition in Low}

\section{Temperature and Low Vacuum Conditions}

\author{
Miika Mattinen $^{* \dagger}$, Peter J. King ${ }^{\dagger}$, Georgi Popov ${ }^{\dagger}$, Jani Hämäläinen ${ }^{\dagger+}$, Mikko J. \\ Heikkilä, ${ }^{\dagger}$ Markku Leskelä, ${ }^{\dagger}$ Mikko Ritala ${ }^{* \dagger}$ \\ ${ }^{\dagger}$ Department of Chemistry, University of Helsinki, P.O. Box 55, FI-00014, Finland \\ \$Present address: Picosun Oy, Masalantie 365, FI-02430, Masala, Finland
}

\begin{abstract}
van der Waals epitaxy holds great promise in producing high-quality films of two-dimensional materials. However, scalable van der Waals epitaxy processes operating at low temperatures and low vacuum conditions are lacking. Herein, atomic layer deposition is used for van der Waals epitaxy of continuous multilayer films of two-dimensional materials $\mathrm{HfS}_{2}, \mathrm{MoS}_{2}, \mathrm{SnS}_{2}$, and $\mathrm{ZrS}_{2}$ on muscovite mica and $\mathrm{PbI}_{2}$ on sapphire at temperatures between 75 and $400{ }^{\circ} \mathrm{C}$. For the metal sulfides on mica, the main epitaxial relation is $(0001)[2 \overline{11} 0] \mathrm{MS}_{2} \|(001)[100]$ mica. Some domains rotated by $30^{\circ}$ are also observed corresponding to the (0001)[1] $\overline{100}] \mathrm{MS}_{2} \|(001)[100]$ mica alignment. In both cases, the presence of $60^{\circ}$ domains (mirror twins) is also expected. For $\mathrm{PbI}_{2}$ on sapphire, the epitaxial relation is $(0001)[2 \overline{11} 0] \mathrm{PbI}_{2} \|(0001)[2 \overline{11} 0] \mathrm{Al}_{2} \mathrm{O}_{3}$ with no evidence of $30^{\circ}$ domains. For all of the studied systems there is relatively large in-plane mosaicity and in the $\mathrm{PbI}_{2} / \mathrm{Al}_{2} \mathrm{O}_{3}$ system some nonepitaxial domains are also observed. The study presents first steps of an approach towards a scalable and semiconductor industry compatible van der Waals epitaxy method.
\end{abstract}


$2 \mathrm{D}$ materials are one of the most active research areas of today due to their unique properties and behavior as well as the potential for ultimate dimensional scaling at (sub)-nanometer level, all arising from their layered crystal structures. After initial groundbreaking studies on first graphene ${ }^{1,2}$ and then $\mathrm{MoS}_{2}{ }^{1,3}$, now tens of different 2D materials are being actively explored and scrutinized for a large variety of applications. ${ }^{4-8}$ Currently, semiconducting $2 \mathrm{D}$ materials - in particular transition metal dichalcogenides (TMDCs) such as $\mathrm{HfS}_{2}, \mathrm{MoS}_{2}, \mathrm{MoSe}_{2}, \mathrm{ZrS}_{2}, \mathrm{WS}_{2}$, and $\mathrm{WSe}_{2}$ - are of great interest due to the instrumental role of semiconductors in (opto)electronics and photovoltaics. ${ }^{5,9-12}$

A major obstacle in the industrial application of 2D materials, however, is the difficulty in controlling thickness and crystal quality over wafer-scale dimensions. Ideally, monolayer-level thickness control and thickness uniformity on large as well as three dimensionally structured substrates should be achieved at low temperatures and at reasonable cost. The quality and domain size of the material should preferably be tunable to cater the needs of different applications. Morphology also plays a crucial role: depending on the substrate and growth conditions 2D materials are commonly observed to grow either flat or tilted at a random angle with respect to the substrate. ${ }^{13-17}$

So far, the highest quality 2D materials are usually produced by mechanically exfoliating natural or high-temperature grown single crystals, but scaling the method for industrial applications is practically impossible. Chemical vapor deposition (CVD) processes operating at high temperatures, often $600-1000{ }^{\circ} \mathrm{C}$, enable deposition of high-quality, monolayer to few-layer $2 \mathrm{D}$ materials. ${ }^{18-20}$ Amorphous substrates, in particular $\mathrm{SiO}_{2}$, are usually used for CVD and a large grain size is pursued through a decrease of the nucleation density by surface treatments and careful control of precursor doses. An alternative approach to minimize grain boundaries uses single crystalline substrates, such as sapphire and mica, in order to enable epitaxial growth of $2 \mathrm{D}$ materials. This approach has been inspired by molecular beam epitaxy (MBE) growth of TMDCs under ultra-high vacuum (UHV) conditions pioneered by Koma ${ }^{21}$ in the 1980s and termed van der Waals (vdW) epitaxy. 
vdW epitaxy can occur when both the film and the substrate have inert, either 2D or passivated 3D surfaces. The presence of only weak van der Waals interactions between the film and the substrate instead of strong covalent or ionic bonding enables growth of epitaxial films of materials with dissimilar lattice constants and even different crystal structures than the substrate without a buildup of strain in the film. ${ }^{22-24}$ Epitaxial nuclei that share the same orientation can stitch together to effectively form a wafer-scale single crystal. However, as outlined above, vdW epitaxy has been mostly limited to UHV (MBE) or high temperature (CVD) conditions, which are difficult or costly to integrate into existing process flows. Atomic layer deposition (ALD) is a thin film deposition technique based on surface reactions of alternately supplied vapor-phase precursors that offers accurate control over film thickness as well as excellent thickness uniformity, conformality, scalability, and repeatability $y^{25-27}$ - attributes which are difficult to achieve with most of the current CVD TMDC processes. Furthermore, ALD processes typically operate at relatively low temperatures from room temperature to $500{ }^{\circ} \mathrm{C}$ and mbar vacuum levels. ALD has already proven its capabilities in depositing various thin films in the semiconductor and other industries. ${ }^{28,29}$ ALD has also emerged as a promising method for the deposition of 2D materials. However, there are still several challenges, such as control of morphology and grain size as summarized in recent reviews. ${ }^{15-17}$

Herein, we deposited several vdW epitaxial 2D materials, including metal sulfides $\mathrm{HfS}_{2},{ }^{30} \mathrm{MoS}_{2},{ }^{31}$ $\mathrm{ReS}_{2},{ }^{32} \mathrm{SnS}_{2},{ }^{33}$ and $\mathrm{ZrS}_{2}{ }^{30}$ as well as a $2 \mathrm{D}$ metal halide $\mathrm{PbI}_{2},{ }^{34}$ by ALD using previously reported processes that operate at relatively low temperatures of 75 to $400{ }^{\circ} \mathrm{C}$. The processes have been previously shown to exhibit self-limiting ALD reactions and typical ALD characteristics including excellent thickness uniformity and conformality, reproducibility, and accurate thickness control. Experimental details are available in Supporting Information. The multilayer, 3-25 nm thick films, were deposited on two common vdW epitaxy substrates, c-plane sapphire and muscovite mica, with $\mathrm{SiO}_{2}$-terminated silicon as a reference substrate. Uniform films were prepared on up to $5 \times 5 \mathrm{~cm}^{2}$ substrates. Remarkably, all of the tested trigonal $1 \mathrm{~T}$ phase metal sulfides $\left(\mathrm{HfS}_{2}, \mathrm{SnS}_{2}\right.$, and $\left.\mathrm{ZrS}_{2}\right)$ grew 
vdW epitaxially on mica but not on sapphire. Using sapphire instead of silicon strengthened the (0001) out-of-plane texture but did not induce the in-plane registration needed for the vdW epitaxy. The situation for the $1 \mathrm{~T}$ phase $\mathrm{PbI}_{2}$ deposited at a very low temperature of $75{ }^{\circ} \mathrm{C}$ was the reverse compared to the $1 \mathrm{~T}$ phase sulfides. The $\mathrm{PbI}_{2}$ films were non-epitaxial on mica, whereas mostly epitaxial films with some non-epitaxial domains were deposited on sapphire. The hexagonal $2 \mathrm{H}$ phase $\mathrm{MoS}_{2}$ also exhibited vdW epitaxial growth on mica. $\operatorname{ReS}_{2}$, which crystallizes in the unique, distorted triclinic 1T' phase, could not be grown epitaxially on mica or sapphire (see Section S9 for more details). The results including the epitaxial relationships are summarized in Table 1 and will be discussed in detail below.

Table 1. Summary of the films of various $2 \mathrm{D}$ materials grown on $\mathrm{SiO}_{2} / \mathrm{Si}$, sapphire, and mica substrates. Fiber texture means non-epitaxial growth with a specified preferred out-of-plane orientation (texture) and random in-plane orientation. $v d W$ epi means in-plane registration in addition to the $(00 l)$ or $(000 l)$ out-of-plane orientation (the four-index notation is used for trigonal and hexagonal materials).

\begin{tabular}{|c|c|c|c|}
\hline $\begin{array}{l}\text { Material } \\
\text { (Structure) }\end{array}$ & $\begin{array}{l}\text { Films on silicon } \\
\left(\text { native } \mathrm{SiO}_{2}\right)\end{array}$ & Films on sapphire & Films on mica \\
\hline HfS $_{2}(1 \mathrm{~T})$ & $\begin{array}{l}\text { weak (0001) fiber } \\
\text { texture }\end{array}$ & weak (0001) fiber texture & $\begin{array}{l}\text { vdW epi: mostly }[2 \overline{11} 0] \text { or }[1 \overline{2} 10] \mathrm{HfS}_{2} \| \\
{[100] \text { mica }\left(0 / 60^{\circ}\right), \text { some } \quad[1 \overline{1} 00] \text { or }} \\
{[0 \overline{1} 10] \mathrm{HfS}_{2} \|[100] \text { mica }\left(30 / 90^{\circ}\right)}\end{array}$ \\
\hline $\mathrm{MoS}_{2}(2 \mathrm{H})$ & $\begin{array}{l}\text { weak (0001) fiber } \\
\text { texture }\end{array}$ & weak (0001) fiber texture & $\begin{array}{l}\text { vdW epi: equally }[2 \overline{11} 0] \text { or }[1 \overline{2} 10] \mathrm{MoS}_{2} \| \\
{[100] \text { mica }\left(0 / 60^{\circ}\right) \text { and }[1 \overline{1} 00] \text { or }} \\
{[0 \overline{1} 10] \mathrm{MoS}_{2} \|[100] \text { mica }\left(30 / 90^{\circ}\right)}\end{array}$ \\
\hline $\mathrm{PbI}_{2}(1 \mathrm{~T})$ & $\begin{array}{l}(0001) \\
\text { texture }\end{array}$ & $\begin{array}{l}\text { vdW epi: }[2 \overline{11} 0] \mathrm{PbI}_{2} \\
{[2 \overline{11} 0] \text { sapphire }\left(0^{\circ}\right), \text { some non- }} \\
\text { epitaxial domains, possibly } 60^{\circ} \\
\text { domains }\end{array}$ & weak (0001) fiber texture \\
\hline
\end{tabular}




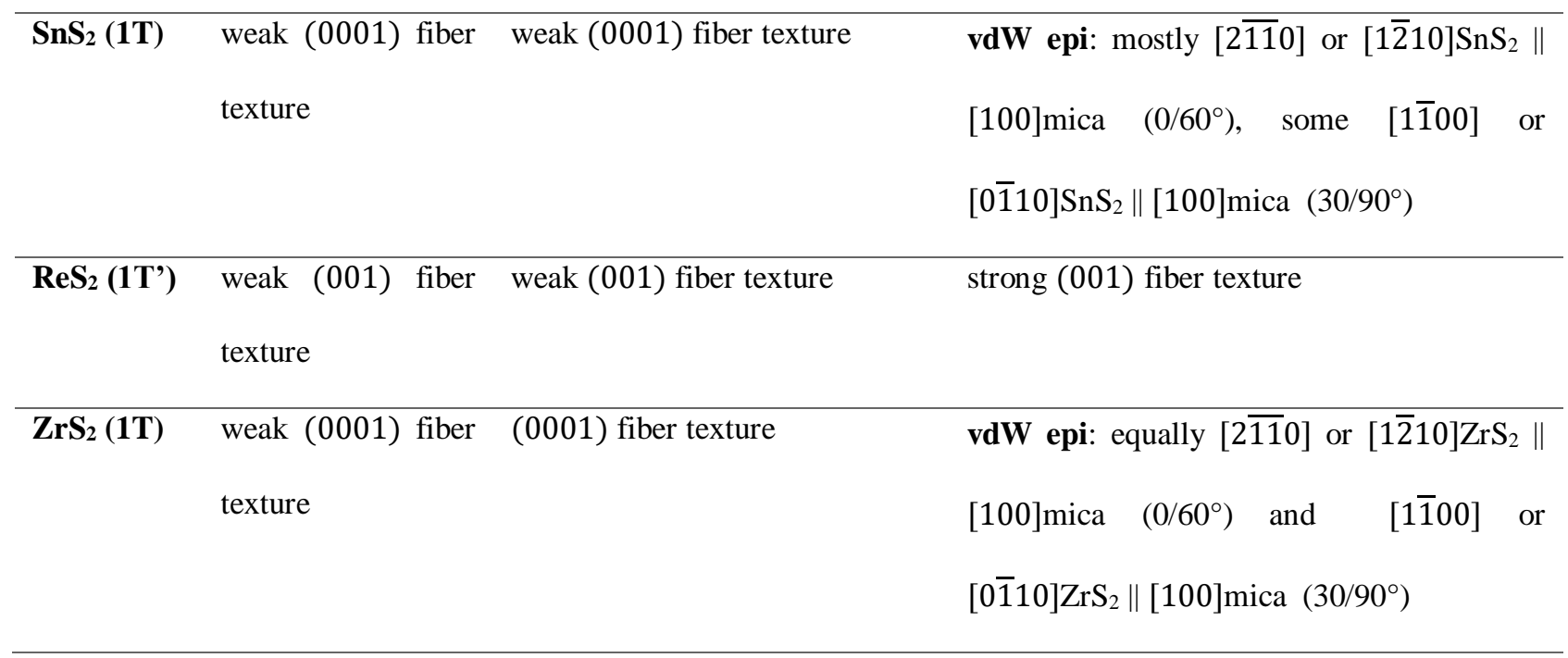

The epitaxy of the trigonal $1 \mathrm{~T}$ metal sulfides on mica is discussed using $\mathrm{ZrS}_{2}$ as an example. XRD measurements showed excellent (0001) $\mathrm{ZrS}_{2} \|$ (0001)mica out-of-plane alignment, as only the ( $000 l)$ reflections of both the film and the substrate were seen in a symmetric $\theta-2 \theta$ measurement and no peaks of the film were observed in an asymmetric grazing incidence (20) measurement (Figure 1a). A rocking curve of the (0001) $\mathrm{ZrS}_{2}$ reflection confirmed the strong (0001) texture with a fullwidth at half-maximum (FWHM) of only $0.16^{\circ}$ (Figure $\mathrm{S} 1$, the instrumental broadening was approximately $0.05^{\circ}$ ).

The in-plane alignment was studied by in-plane XRD measurements of planes perpendicular to the (0001) plane. ${ }^{35} \mathrm{~A} \phi$ scan of the $(10 \overline{1} 0) \mathrm{ZrS}_{2}$ reflection resulted in twelve peaks over a full $360^{\circ}$ rotation, while six peaks were observed for the (020)mica reflection (Figure 1b). Normally, peaks are expected every $\frac{360}{n}$ degrees for a plane of n-fold symmetry. The observation of six peaks every $60^{\circ}$ from mica, which has only mirror symmetry, has been explained by the presence of different stacking orientations. ${ }^{36}$ Although the $1 \mathrm{~T}$ metal sulfides have only three-fold rotational symmetry around the c-axis, the $(10 \overline{1} 0)$ plane has six-fold symmetry, which results in six peaks from a single in-plane orientation. Thus, at least two orientations of $\mathrm{ZrS}_{2}$ were present in rather similar amounts, one with [2 $\overline{11} 0] \mathrm{ZrS}_{2} \|[100]$ mica alignment and the other one rotated by $30^{\circ}$ with respect to the first 
one, i.e. $[1 \overline{1} 00] \mathrm{ZrS}_{2} \|[100]$ mica. Rotation by $60^{\circ}$, which in this case is equivalent to the formation of mirror twins, is likely to occur considering the mirror symmetry of the mica surface as well as the mismatch in the symmetry between $\mathrm{ZrS}_{2}$ and mica. ${ }^{37}$ Thus, $[1 \overline{2} 10] \mathrm{ZrS}_{2}\left(60^{\circ}\right)$ or $[0 \overline{1} 10] \mathrm{ZrS}_{2}\left(90^{\circ}\right) \|$ [100]mica domains are expected to be present.

The $\mathrm{ZrS}_{2}$ as well as $\mathrm{HfS}_{2}$ and $\mathrm{SnS}_{2}$ films deposited on mica were smooth with no clear evidence of the different domains offered by the morphology (Figure 1c). However, an epitaxial $\mathrm{SnS}_{2}$ sample prepared under conditions favoring island-like growth confirmed the presence of four main orientations at $30^{\circ}$ intervals (Figure S2). Fortunately, the twin grain boundaries occurring between 0 , 30 , 60, and $90^{\circ}$ domains have not been observed to degrade the electrical properties of $2 \mathrm{D}$ dichalcogenides dramatically. ${ }^{38,39}$ The relatively large FWHMs of approximately 9 and $14^{\circ}$ for the in-plane peaks of the $0 / 60^{\circ}$ and $30 / 90^{\circ}$ domains suggest considerable rotational disorder of the nominally epitaxial $\mathrm{ZrS}_{2}$ domains.

The island size in the aforementioned discontinuous $\mathrm{SnS}_{2}$ film was approximately $200 \pm 100 \mathrm{~nm}$ according to AFM (Figure $\mathrm{S} 2$ ). For a smooth, $5 \mathrm{~nm}$ thick $\mathrm{SnS}_{2}$ film on mica, the domain size was estimated as $70 \mathrm{~nm}$ using in-plane $\mathrm{XRD}$ (Figure S3). Comparable $\mathrm{SnS}_{2}$ films deposited on sapphire and $\mathrm{SiO}_{2} / \mathrm{Si}$ had average domain (crystallite) sizes of $23 \mathrm{~nm}$ and $14 \mathrm{~nm}$. Similarly, the average domain sizes of $7 \mathrm{~nm}$ thick $\mathrm{ZrS}_{2}$ films were estimated at 40, 17, and $11 \mathrm{~nm}$ on mica, sapphire, and $\mathrm{SiO}_{2} / \mathrm{Si}$, respectively. Thus, using mica improves film quality not only through the epitaxial arrangement but also by the increase of domain size.

Figure 1d schematically illustrates the different orientations of the $1 \mathrm{~T}$ phase metal sulfides on the mica surface (alternative views are given in Figures S4 and S5). Despite different crystal structures, similarities in the mica (monoclinic, space group 15, C2/c, JCPDS-ICDD PDF 72-1503) and $\mathrm{MS}_{2}$ (trigonal, space group 164, $P \overline{3} m 1$, JCPDS-ICDD PDF 28-444, 23-677, and 11-679 for $\mathrm{HfS}_{2}, \mathrm{SnS}_{2}$, and $\mathrm{ZrS}_{2}$ ) surfaces can be observed. The bottom sulfur layer of $\mathrm{MS}_{2}$ has six-fold symmetry in contrast 
to three-fold symmetry of a $\mathrm{MS}_{2}$ monolayer, i.e. a S-M-S trilayer. The cleaved muscovite mica surface consists of silicon and oxygen atoms and is nearly hexagonal, although strictly speaking it only has mirror symmetry due to small corrugations and variations in atomic positions. ${ }^{36,40}$

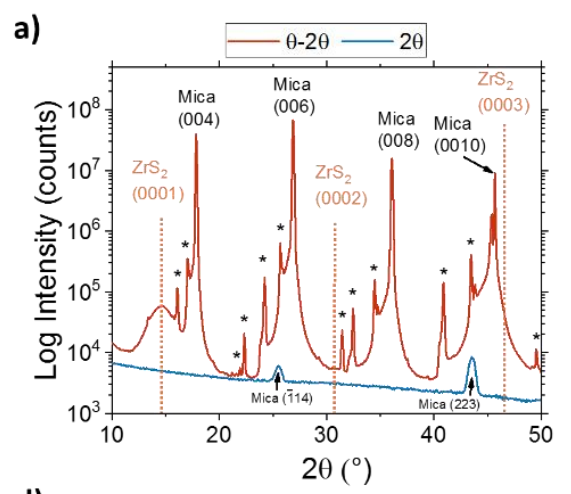

d)

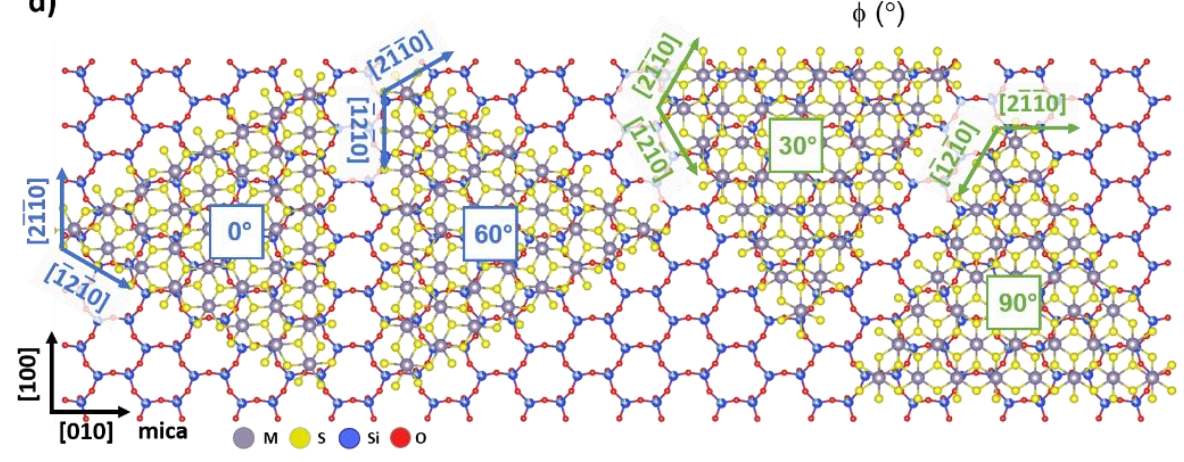

c)
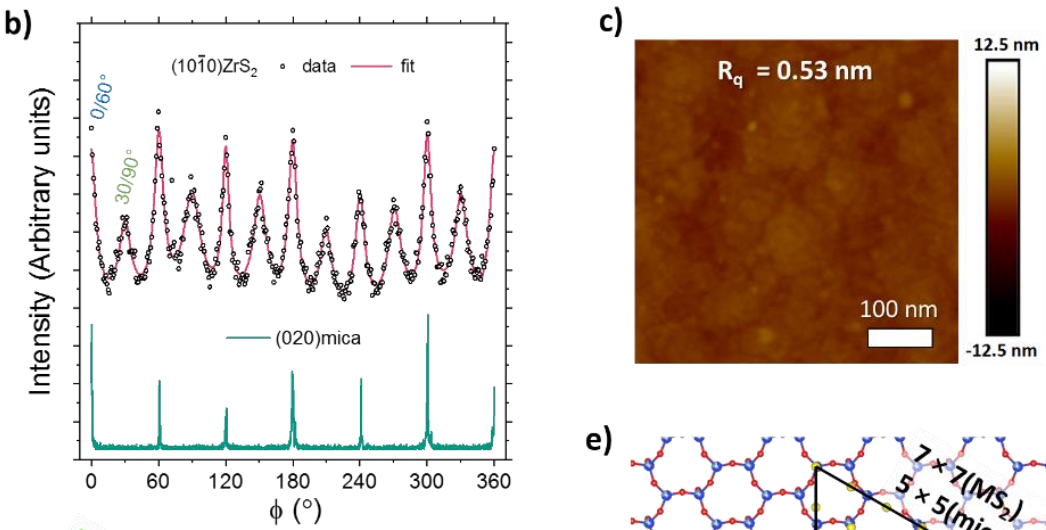

e)

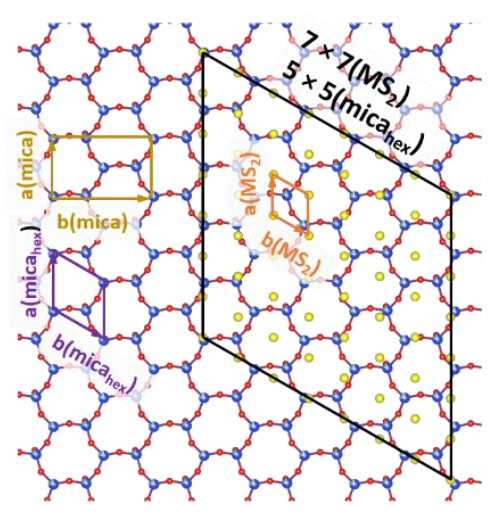

Figure 1. vdW epitaxy of $\mathrm{MS}_{2}$ films on mica with $\mathrm{ZrS}_{2}$ as an example. a) Out-of-plane $\mathrm{X}$-ray

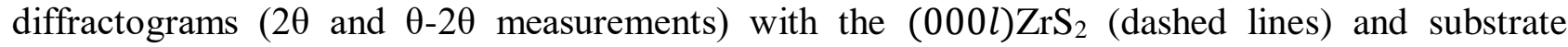
reflections marked (asterisks mark substrate peaks originating from $\mathrm{W} L \alpha$ and $\mathrm{Cu} K \beta$ radiation, see Section S1). b) In-plane $\phi$ scans of $(10 \overline{1} 0) \mathrm{ZrS}_{2}\left(28.2^{\circ} 2 \theta \chi\right)$ and (020)mica $\left(19.7^{\circ} 2 \theta \chi\right)$ reflections. The data have been offset vertically for clarity. c) AFM image of a $7 \mathrm{~nm} \mathrm{ZrS}_{2}$ film grown on mica at $400{ }^{\circ} \mathrm{C}$ using 1000 ALD cycles. d) Schematic of the possible $\mathrm{MS}_{2}(\mathrm{M}=\mathrm{Hf}$, Sn, $\mathrm{Zr})$ domains on mica (for clarity, only one $\mathrm{MS}_{2}$ layer is shown). e) Schematic of a possible CSL between mica and a $0^{\circ}$ $\mathrm{MS}_{2}$ domain (only bottom sulfur layer is shown).

Approximating the mica surface as hexagonal allows finding coincidence site lattices (CSLs), where only some of the lattice points of $\mathrm{MS}_{2}$ and mica coincide. Due to the weak interactions between the film and the substrate, the CSL concept is particularly relevant for the vdW epitaxy. ${ }^{41-43}$ For the $0 / 60^{\circ}$ 
domains, a $7 \times 7$ supercell of $\mathrm{MS}_{2}$ shows only a $-1.0 \%\left(\mathrm{ZrS}_{2}\right)$ to $-1.8 \%\left(\mathrm{HfS}_{2}\right)$ lattice mismatch with a $5 \times 5$ hexagonal supercell of mica (Figures 1e and S6) compared to a lattice mismatch of approximately $-30 \%$ for the unit cells of $\mathrm{MS}_{2}$ and mica. For the $30 / 90^{\circ}$ domains, CSL with less than $2 \%$ mismatch can also be found (Figure S6). The lattice mismatches were calculated using reported lattice parameters. Previously, the mica surface has been observed to relax once cleaved. ${ }^{44,45}$ Furthermore, Kuwahara ${ }^{45}$ observed approximately $\pm 5 \%$ variation in the unit cell dimensions across a cleaved mica surface. The first $\mathrm{MS}_{2}$ layer may also be strained to better match the mica surface, although no obvious strain was observed in the bulk of the films. Thus, it is difficult to predict the actual interface structure.

Films of all of the studied 1T phase metal sulfides, i.e. $\mathrm{HfS}_{2}, \mathrm{SnS}_{2}$, and $\mathrm{ZrS}_{2}$, were epitaxial on mica with the same in-plane alignments for the majority of the crystallites (Figure 2). In terms of the outof-plane orientation, all of these materials were strongly (0001) t with FWHMs of $0.15-0.17^{\circ}$ (Figures S1, S7, and S8). In-plane, both $0 / 60^{\circ}$ and $30 / 90^{\circ}$ domains were observed for all of the materials, although in different amounts. For $\mathrm{SnS}_{2}$, the amount of the $30 / 90^{\circ}$ domains was the lowest, whereas for $\mathrm{ZrS}_{2}$ nearly identical amounts of the $0 / 60^{\circ}$ and $30 / 90^{\circ}$ domains were observed. The intensity ratios of the $0 / 60^{\circ}$ to $30 / 90^{\circ}$ domains obtained by integrating the peak areas were approximately 4:1, 3:1, and 1:1 for $\mathrm{SnS}_{2}, \mathrm{HfS}_{2}$, and $\mathrm{ZrS}_{2}$, respectively. Furthermore, differences in the FWHMs were observed. The $0 / 60^{\circ}$ domains of $\mathrm{ZrS}_{2}$ exhibited the smallest, although still quite large, mosaicity with a FWHM of approximately $9^{\circ}$ compared to $14^{\circ}$ and $19^{\circ}$ for $\mathrm{SnS}_{2}$ and $\mathrm{HfS}_{2}$. Similar in-plane FWHMs have been observed in several reports on vdW epitaxy. ${ }^{46-48}$ However, using a three-step CVD process at $800{ }^{\circ} \mathrm{C}$, Zhang et al. ${ }^{49}$ obtained an in-plane FWHM of only $0.28^{\circ}$ for $\mathrm{WSe}_{2}$ on sapphire. Thus, we believe that the in-plane disorder can be decreased by further optimization of our process.

$\mathrm{MoS}_{2}$ crystallizes in the hexagonal $2 \mathrm{H}$ structure (space group 194, P63/mmc, JCPDS-ICDD PDF 37-1492) and has a much smaller in-plane lattice constant ( $\mathrm{a}, \mathrm{b}=3.16 \AA$ ) compared to $\mathrm{HfS}_{2}, \mathrm{SnS}_{2}$, 
and $\mathrm{ZrS}_{2} . \mathrm{MoS}_{2}$ films grew vdW epitaxially on mica, although with somewhat weaker (0001) outof-plane texture and rougher surface as compared to the 1T metal sulfides studied above (Figures S9S11). Non-epitaxial, rough films were deposited on sapphire and $\mathrm{SiO}_{2} / \mathrm{Si}$ (Figure $\mathrm{S} 12$ ). Approximately equal amounts of $[2 \overline{11} 0]$ or $[1 \overline{2} 10] \mathrm{MoS}_{2} \|[100] \mathrm{mica}\left(0 / 60^{\circ}\right)$ and $[1 \overline{1} 00]$ or $[0 \overline{1} 10] \mathrm{MoS}_{2} \|[100]$ mica $\left(30 / 90^{\circ}\right)$ orientations were observed (Figure S13-S15). The nearly $-40 \%$ lattice mismatch is reduced to $-2.4 \%$ for a $8 \times 8 \mathrm{MoS}_{2}$ supercell on a $5 \times 5$ hexagonal mica supercell for the $0 / 60^{\circ}$ domains, whereas a $\sqrt{3} \times \sqrt{3} \mathrm{MoS}_{2}$ supercell on a $1 \times 1$ hexagonal mica unit cell results in a relatively small mismatch of $5.8 \%$ for the $30 / 90^{\circ}$ domains (Figure S16).

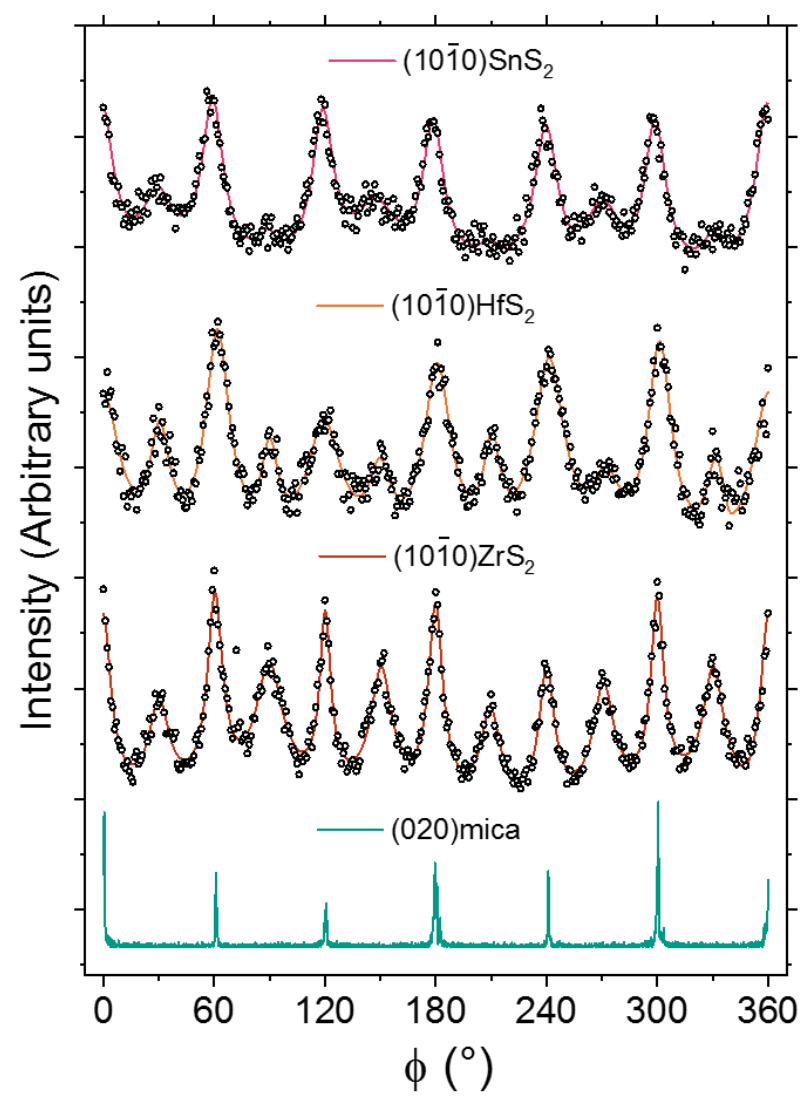

Figure 2. Comparison of different $\mathbf{M S}_{2}$ films on mica. In-plane $\phi$ scans of the $(10 \overline{1} 0)$ reflections of $\mathrm{SnS}_{2}\left(28.35^{\circ} 2 \theta \chi\right), \mathrm{HfS}_{2}\left(28.6^{\circ} 2 \theta \chi\right)$, and $\mathrm{ZrS}_{2}\left(28.2^{\circ} 2 \theta \chi\right)$ films. For clarity, only a single measurement of the (020)mica reflection is shown $\left(19.7^{\circ} 2 \theta \chi\right)$, although the registration was individually checked for each sample. The data has been offset vertically. 
On the c-plane sapphire, i.e. (0001) $\alpha-\mathrm{Al}_{2} \mathrm{O}_{3}$, only the $\mathrm{PbI}_{2}$ films could be grown epitaxially, whereas all of the other materials formed non-epitaxial films that were more strongly (0001) textured compared to the amorphous $\mathrm{SiO}_{2} / \mathrm{Si}$ (see Section $\mathrm{S} 10$ ). The failure to obtain epitaxial growth might be ascribed to the relatively low deposition temperatures compared to the earlier reports of vdW epitaxy on sapphire (see Section S13 for a literature survey). It has been suggested that epitaxy of TMDCs on sapphire is enabled by chemical reduction of the sapphire surface in a chalcogen environment at high temperatures, ${ }^{50}$ or by formation of a chalcogen-terminated surface layer on the sapphire. ${ }^{51}$ Both are be unlikely to occur under our mild ALD conditions. Further comparing $\mathrm{PbI}_{2}$ to the studied $1 \mathrm{~T}$ sulfides, it is interesting that $\mathrm{PbI}_{2}$ films on mica, unlike the $1 \mathrm{~T}$ sulfides, were not epitaxial but composed of rather randomly oriented domains (Figure S24).

In literature, the (0001)sapphire surface is suggested to be Al-terminated over a range of preparation conditions. ${ }^{52,53}$ Thus, we consider an Al-terminated surface with bulk atomic positions, i.e. with a somewhat corrugated hexagonal Al layer on top and a slightly distorted hexagonal oxygen layer beneath it. The successful epitaxy of $\mathrm{PbI}_{2}$ on sapphire might be due to the large in-plane lattice constants of $\mathrm{PbI}_{2}$ (a,b = $4.56 \AA$; trigonal, space group 164, $P \overline{3} m 1$, JCPDS-ICDD PDF 7-235), which are approximately $25 \%$ larger compared to $\mathrm{HfS}_{2}, \mathrm{SnS}_{2}$, and $\mathrm{ZrS}_{2}$ and only $4.2 \%$ smaller than those of $\alpha-\mathrm{Al}_{2} \mathrm{O}_{3}(\mathrm{a}, \mathrm{b}=4.76 \AA$ using the conventional hexagonal unit cell; trigonal, space group $167, R \overline{3} c$, JCPDS-ICDD PDF 46-1212). This enables epitaxial growth with a simple 1:1 relationship between the unit cells of $\mathrm{PbI}_{2}$ and sapphire as shown in Figure 3a (tilted view in Figure $\mathrm{S} 25$ ).

The $\mathrm{PbI}_{2} /$ sapphire system was initially studied by an in-plane pole figure measured at $25.95^{\circ} 2 \theta$ (Figure 3b), which corresponds to the asymmetric (1011) $\mathrm{PbI}_{2}$ reflection but is also close enough to the asymmetric (0112)sapphire reflection to yield information on the film/substrate registration. Three sharp peaks over a $360^{\circ}$ rotation were observed for the sapphire reflection, whereas six broader peaks were seen for $\mathrm{PbI}_{2}$, both being as expected for a single in-plane orientation considering the 
symmetry of the reflections. The alignment of the $(10 \overline{1} 1) \mathrm{PbI}_{2}$ and $(01 \overline{1} 2)$ sapphire reflections corresponds to the (001)[2 $\overline{11} 0] \mathrm{PbI}_{2} \|(001)[2 \overline{11} 0] \mathrm{Al}_{2} \mathrm{O}_{3}$ epitaxial relation, i.e. parallel alignment of all the unit cell axes of $\mathrm{PbI}_{2}$ and sapphire as expected from the relatively small lattice mismatch between the film and the substrate. Presence of $\mathrm{PbI}_{2}$ mirror twins, i.e. (001) [12 10$] \mathrm{PbI}_{2} \|$ (001) $[2 \overline{11} 0] \mathrm{Al}_{2} \mathrm{O}_{3}$, could not be ruled out, however. Contrary to the metal sulfides grown on mica, no $30 / 90^{\circ}$ domains were observed. The relatively broad peaks in $\beta$ (FWHM $13^{\circ}$, Figure 3c) and $\alpha$ scans (FWHM $9^{\circ}$, Figure 3d) extracted from the in-plane pole figure suggest disorder in both the inplane and out-of-plane orientations, respectively. The elevated background in the in-plane $\beta$ direction as well as out-of-plane XRD and the presence of some vertical flakes on the film surface show that some of the domains are not epitaxially aligned (see also Figures S26-S28). The epitaxial $\mathrm{PbI}_{2}$ films on sapphire are much rougher compared to the $1 \mathrm{~T}$ sulfides on mica due to the pyramidal shape of the $\mathrm{PbI}_{2}$ grains (Figure S28). In-plane XRD measurements confirmed the in-plane alignment, the absence of $30 / 90^{\circ}$ domains and the presence of some non-epitaxial domains (Figure 3e). Considering the very low deposition temperature of $75^{\circ} \mathrm{C}$, there is further room for improvement of the epitaxial quality by post-deposition annealing, although the easy sublimation of $\mathrm{PbI}_{2}$ should be kept in mind. To the best of our knowledge, epitaxy in the $\mathrm{PbI}_{2} /$ sapphire system has not been reported before, whereas $\mathrm{PbI}_{2}$ has been grown epitaxially on mica, Se-terminated GaAs(111), and various TMDCs (Table S2). 
a)

Bottom I layer
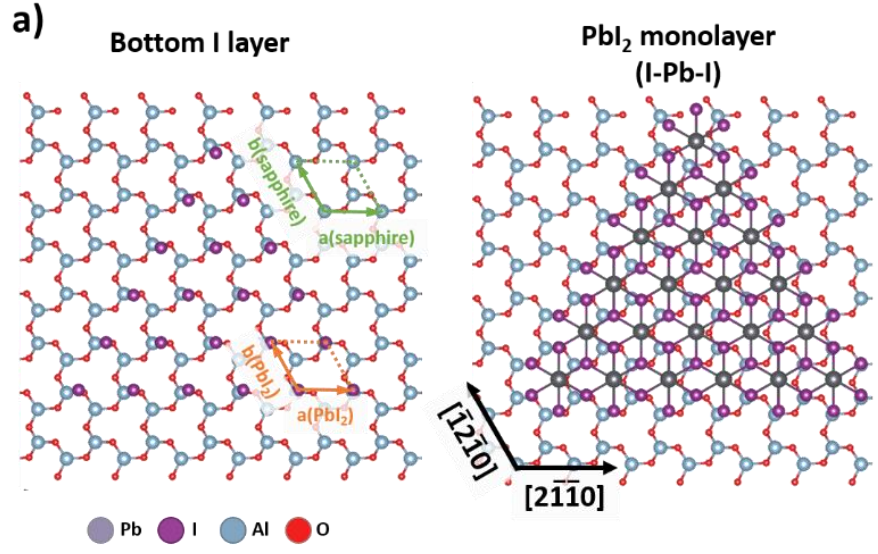

b)
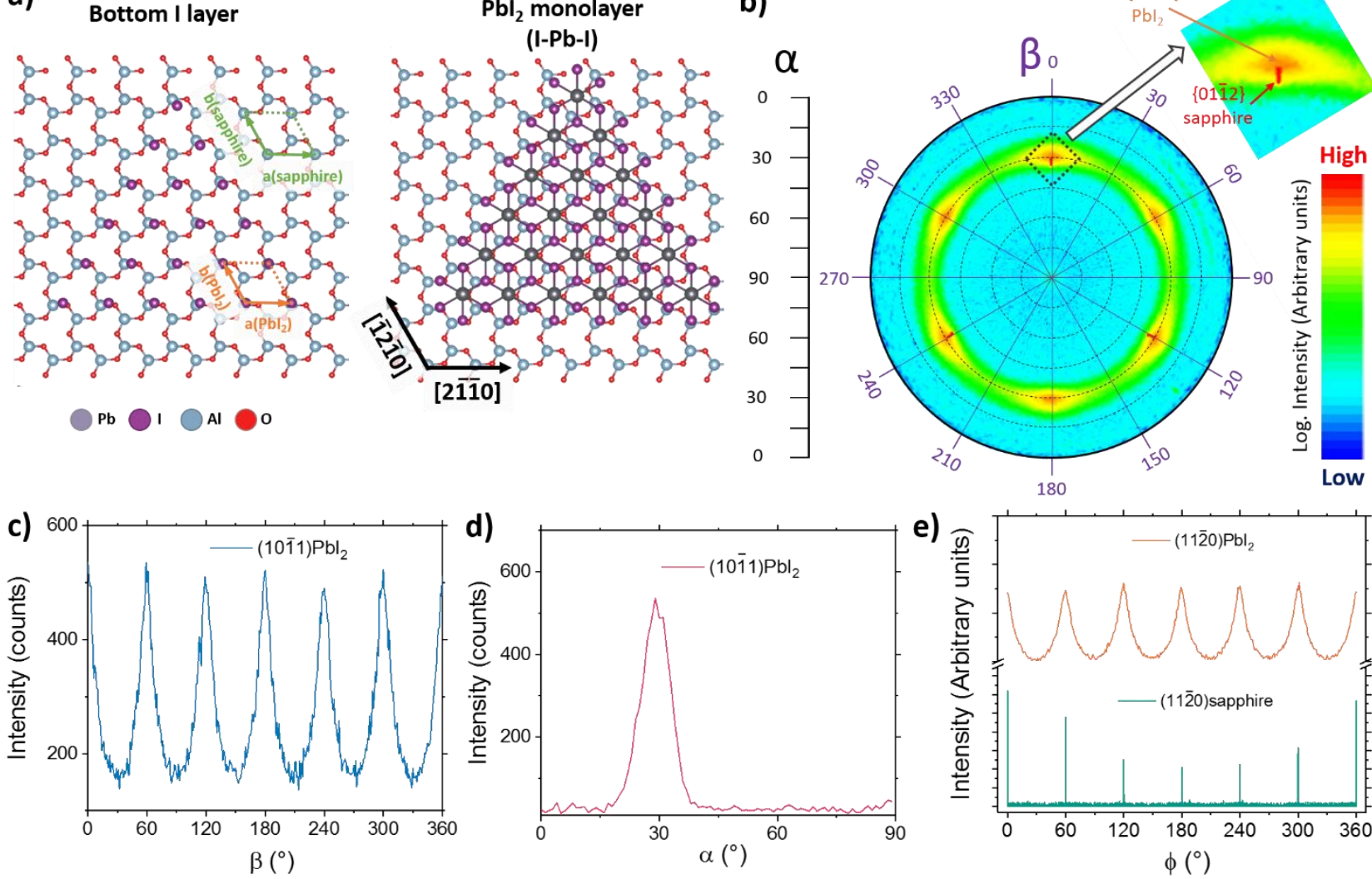

Figure 3. vdW epitaxy of $\mathrm{PbI}_{2}$ on sapphire. a) Schematic of the epitaxial alignment of $\mathrm{PbI}_{2}$ on sapphire with either the bottom iodine layer or a $\mathrm{PbI}_{2}$ monolayer shown on the (0001)sapphire surface. Characterization of an epitaxial $\mathrm{PbI}_{2}$ film on sapphire. b) In-plane pole figure at $25.95{ }^{\circ} 2 \theta$ inset showing a zoomed view of the dashed area with both the $\{01 \overline{1} 2\}$ sapphire and $\{10 \overline{1} 1\} \mathrm{PbI}_{2}$ reflections visible. Extracted c) $\beta$ scan along $\alpha=29^{\circ}$ and d) $\alpha$ scan along $\beta=180^{\circ}$. e) In-plane $\phi$ scans of the $(11 \overline{2} 0) \mathrm{PbI}_{2}\left(39.45^{\circ} 2 \theta \chi\right)$ and $(11 \overline{2} 0)$ sapphire $\left(37.65^{\circ} 2 \theta \chi\right)$ reflections. The data in e) has been offset vertically for clarity.

In conclusion, we have achieved vdW epitaxial growth of various $2 \mathrm{D}$ metal sulfides $\left(\mathrm{HfS}_{2}, \mathrm{MoS}_{2}\right.$, $\mathrm{SnS}_{2}$, and $\mathrm{ZrS}_{2}$ ) on muscovite mica and $\mathrm{PbI}_{2}$ on sapphire using ALD. The films were deposited at low temperatures $\left(75-400{ }^{\circ} \mathrm{C}\right)$ and low vacuum conditions ( $\left.\sim 5 \mathrm{mbar}\right)$ in contrast to the previously used high temperatures and/or UHV conditions. Furthermore, using our approach, it is possible to benefit from the favorable characteristics of ALD including accurate and reproducible control of thickness, 
scalability, and excellent thickness uniformity and conformality. Epitaxial growth was observed using different classes of ALD precursors at different temperatures, which shows the generality of the approach and opens new avenues for the future research, including growth of heterostructures. In the future, we envision tuning the growth conditions, pre- and post-treatments as well as testing different substrates in order to reduce the number of different epitaxial orientations and in-plane mosaicity.

\section{Associated Content}

Supporting Information: Experimental details of film deposition and characterization, additional XRD characterization and schematics on the epitaxy of $\mathrm{HfS}_{2}, \mathrm{SnS}_{2}$, and $\mathrm{ZrS}_{2}$ films on mica, characterization of $\mathrm{MoS}_{2}$ and $\mathrm{ReS}_{2}$ films on $\mathrm{Si}$, sapphire, and mica including details on the vdW epitaxy of $\mathrm{MoS}_{2}$ on mica, additional characterization of $\mathrm{PbI}_{2}$ films on sapphire, and discussion of previously reported vdW epitaxy processes.

\section{Author Information}

\section{Corresponding Author}

*E-mail: miika.mattinen@ @elsinki.fi (M. Mattinen)

*E-mail: mikko.ritala@helsinki.fi (M. Ritala)

\section{Acknowledgements}

The research was supported by ASM Microchemistry. 


\section{References}

(1) Novoselov, K. S.; Geim, A. K.; Morozov, S. V.; Jiang, D.; Zhang, Y.; Dubonos, S. V.; Grigorieva, I. V.; Firsov, A. A. Electric Field Effect in Atomically Thin Carbon Films. Science 2004, 306, 666-669.

(2) Allen, M. J.; Tung, V. C.; Kaner, R. B. Honeycomb Carbon: A Review of Graphene. Chem. Rev. 2010, 110, 132-145.

(3) Radisavljevic, B.; Radenovic, A.; Brivio, J.; Giacometti, V.; Kis, A. Single-Layer MoS 2 Transistors. Nat. Nanotechnol. 2011, 6, 147-150.

(4) Zhang, K.; Feng, Y.; Wang, F.; Yang, Z.; Wang, J. Two Dimensional Hexagonal Boron Nitride (2D-hBN): Synthesis, Properties and Applications. J. Mater. Chem. C 2017, 5, 11992-12022.

(5) Samadi, M.; Sarikhani, N.; Zirak, M.; Zhang, H.; Zhang, H.-L.; Moshfegh, A. Z. Group 6 Transition Metal Dichalcogenide Nanomaterials: Synthesis, Applications and Future Perspectives. Nanoscale Horizons 2018, 3, 90-204.

(6) Han, G. H.; Duong, D. L.; Keum, D. H.; Yun, S. J.; Lee, Y. H. Van Der Waals Metallic Transition Metal Dichalcogenides. Chem. Rev. 2018, 118, 6297-6336.

(7) Hossain, M.; Zhao, Z.; Wen, W.; Wang, X.; Wu, J.; Xie, L. Recent Advances in TwoDimensional Materials with Charge Density Waves: Synthesis, Characterization and Applications. Crystals 2017, 7, 298.

(8) Dai, J.; Li, M.; Zeng, X. C. Group IVB Transition Metal Trichalcogenides: A New Class of 2D Layered Materials beyond Graphene. Wiley Interdiscip. Rev. Comput. Mol. Sci. 2016, 6, 211-222.

(9) Song, X.; Guo, Z.; Zhang, Q.; Zhou, P.; Bao, W.; Zhang, D. W. Progress of Large-Scale Synthesis and Electronic Device Application of Two-Dimensional Transition Metal Dichalcogenides. Small 2017, 13, 1700098.

(10) Yan, C.; Gong, C.; Wangyang, P.; Chu, J.; Hu, K.; Li, C.; Wang, X.; Du, X.; Zhai, T.; Li, Y.; et al. 2D Group IVB Transition Metal Dichalcogenides. Adv. Funct. Mater. 2018, 28, 1803305.

(11) Das, S.; Pandey, D.; Thomas, J.; Roy, T. The Role of Graphene and Other 2D Materials in Solar Photovoltaics. Adv. Mater. 2018, 31, 1802722.

(12) Schwierz, F.; Pezoldt, J.; Granzner, R. Two-Dimensional Materials and Their Prospects in Transistor Electronics. Nanoscale 2015, 7, 8261-8283.

(13) Pakdel, A.; Bando, Y.; Golberg, D. Nano Boron Nitride Flatland. Chem. Soc. Rev. 2014, 43, 934-959.

(14) You, J.; Hossain, M. D.; Luo, Z. Synthesis of 2D Transition Metal Dichalcogenides by Chemical Vapor Deposition with Controlled Layer Number and Morphology. Nano Converg. 2018, 5, 26.

(15) Hao, W.; Marichy, C.; Journet, C. Atomic Layer Deposition of Stable 2D Materials. 2D Mater. 2019, 6, 012001.

(16) Leskelä, M.; Mattinen, M.; Ritala, M. Review Article: Atomic Layer Deposition of Optoelectronic Materials. J. Vac. Sci. Technol. B 2019, 37, 030801. 
(17) Huang, Y.; Liu, L. Recent Progress in Atomic Layer Deposition of Molybdenum Disulfide: A Mini Review. Sci. China Mater. 2019, 62, 913-924.

(18) Ji, Q.; Zhang, Y.; Zhang, Y.; Liu, Z. Chemical Vapour Deposition of Group-VIB Metal Dichalcogenide Monolayers: Engineered Substrates from Amorphous to Single Crystalline. Chem. Soc. Rev. 2015, 44, 2587-2602.

(19) Cai, Z.; Liu, B.; Zou, X.; Cheng, H.-M. Chemical Vapor Deposition Growth and Applications of Two-Dimensional Materials and Their Heterostructures. Chem. Rev. 2018, 118, 6091-6133.

(20) Bosi, M. Growth and Synthesis of Mono and Few-Layers Transition Metal Dichalcogenides by Vapour Techniques: A Review. RSC Adv. 2015, 8, 75500-75518.

(21) Koma, A.; Sunouchi, K.; Miyajima, T. Fabrication and Characterization of Heterostructures with Subnanometer Thickness. Microelectron. Eng. 1984, 2, 129-136.

(22) Koma, A. Van Der Waals Epitaxy - a New Epitaxial Growth Method for a Highly LatticeMismatched System. Thin Solid Films 1992, 216, 72-76

(23) Walsh, L. A.; Hinkle, C. L. Van Der Waals Epitaxy: 2D Materials and Topological Insulators. Appl. Mater. Today 2017, 9, 504-515.

(24) Walsh, L. A.; Addou, R.; Wallace, R. M.; Hinkle, C. L. Molecular Beam Epitaxy of Transition Metal Dichalcogenides. In Molecular Beam Epitaxy; Henini, M., Ed.; Elsevier: Amsterdam, Netherlands, 2018; pp 515-531.

(25) George, S. M. Atomic Layer Deposition: An Overview. Chem. Rev. 2010, 110, 111-131.

(26) Ritala, M.; Niinistö, J. Atomic Layer Deposition. In Chemical Vapour Deposition: Precursors, Processes and Applications; Jones, A. C., Hitchman, M. L., Eds.; Royal Society of Chemistry: Cambridge, 2009; pp 158-206.

(27) Leskelä, M.; Niinistö, J.; Ritala, M. Atomic Layer Deposition. In Comprehensive Materials Processing; Hashmi, S., Cameron, D., Eds.; Elsevier: Amsterdam, 2014; Vol. 4, pp 101-123.

(28) Ritala, M.; Niinistö, J. Industrial Applications of Atomic Layer Deposition. ECS Trans. 2009, $25(8), 641-652$.

(29) Raaijmakers, I. J. Current and Future Applications of ALD in Micro-Electronics. ECS Trans. 2011, 41 (2), 3-17.

(30) Mattinen, M.; Popov, G.; Vehkamäki, M.; King, P. J.; Mizohata, K.; Jalkanen, P.; Räisänen, J.; Leskelä, M.; Ritala, M. Atomic Layer Deposition of Emerging 2D Semiconductors, $\mathrm{HfS}_{2}$ and $\mathrm{ZrS}_{2}$, for Optoelectronics. Chem. Mater. 2019, 31, 5713-5724.

(31) Mattinen, M.; Hatanpää, T.; Sarnet, T.; Mizohata, K.; Meinander, K.; King, P. J.; Khriachtchev, L.; Räisänen, J.; Ritala, M.; Leskelä, M. Atomic Layer Deposition of Crystalline $\mathrm{MoS}_{2}$ Thin Films: New Molybdenum Precursor for Low-Temperature Film Growth. Adv. Mater. Interfaces 2017, 4, 1700213.

(32) Hämäläinen, J.; Mattinen, M.; Mizohata, K.; Meinander, K.; Vehkamäki, M.; Räisänen, J.; Ritala, M.; Leskelä, M. Atomic Layer Deposition of Rhenium Disulfide. Adv. Mater. 2018, 30, 1703622 .

(33) Mattinen, M.; King, P. J.; Khriachtchev, L.; Meinander, K.; Gibbon, J. T.; Dhanak, V. R.; Räisänen, J.; Ritala, M.; Leskelä, M. Low-Temperature Wafer-Scale Deposition of Continuous 2D SnS 2 Films. Small 2018, 14, 1800547. 
(34) Popov, G.; Mattinen, M.; Hatanpää, T.; Vehkamäki, M.; Kemell, M.; Mizohata, K.; Räisänen, J.; Ritala, M.; Leskelä, M. Atomic Layer Deposition of $\mathrm{PbI}_{2}$ Thin Films. Chem. Mater. 2019, $31,1101-1109$.

(35) Kobayashi, S. X-Ray Thin Film Measurements Techniques IV. In-Plane XRD Measurements. Rigaku J. 2010, 26, 3-11.

(36) Simbrunner, C.; Hernandez-Sosa, G.; Oehzelt, M.; Djuric, T.; Salzmann, I.; Brinkmann, M.; Schwabegger, G.; Watzinger, I.; Sitter, H.; Resel, R. Epitaxial Growth of Sexithiophene on Mica Surfaces. Phys. Rev. B. 2011, 83, 115443.

(37) Grundmann, M.; Böntgen, T.; Lorenz, M. Occurrence of Rotation Domains in Heteroepitaxy. Phys. Rev. Lett. 2010, 105, 146102.

(38) van der Zande, A. M.; Huang, P. Y.; Chenet, D. A; Berkelbach, T. C.; You, Y.; Lee, G.-H.; Heinz, T. F.; Reichman, D. R.; Muller, D. A.; Hone, J. C. Grains and Grain Boundaries in Highly Crystalline Monolayer Molybdenum Disulphide. Nat. Mater. 2013, 12, 554-561.

(39) Dumcenco, D.; Ovchinnikov, D.; Marinov, K.; Lazic, P.; Gibertini, M.; Marzari, N.; Sanchez, O. L.; Kung, Y.-C.; Krasnozhon, D.; Chen, M.-W.; Bertolazzi, S.; Gillet, P.; Fontcuberta i Morral, A.; Radenovic, A.; Kis, A. Large-Area Epitaxial Monolayer $\mathrm{MoS}_{2}$. ACS Nano 2015, 9, 4611-4620.

(40) Christenson, H. K.; Thomson, N. H. The Nature of the Air-Cleaved Mica Surface. Surf. Sci. Rep. 2016, 71, 367-390.

(41) Boschker, J. E.; Galves, L. A.; Flissikowski, T.; Lopes, J. M. J.; Riechert, H.; Calarco, R. Coincident-Site Lattice Matching during van Der Waals Epitaxy. Sci. Rep. 2016, 5, 18079.

(42) Wang, S. F.; Fong, W. K.; Wang, W.; Surya, C. Growth of Highly Textured SnS on Mica Using an SnSe Buffer Layer. Thin Solid Films 2014, 564, 206-212.

(43) Koda, D. S.; Bechstedt, F.; Marques, M.; Teles, L. K. Coincidence Lattices of 2D Crystals: Heterostructure Predictions and Applications. J. Phys. Chem. C 2016, 120, 10895-10908.

(44) Fukuma, T.; Ueda, Y.; Yoshioka, S.; Asakawa, H. Atomic-Scale Distribution of Water Molecules at the Mica-Water Interface Visualized by Three-Dimensional Scanning Force Microscopy. Phys. Rev. Lett. 2010, 104, 016101.

(45) Kuwahara, Y. Comparison of the Surface Structure of the Tetrahedral Sheets of Muscovite and Phlogopite by AFM. Phys. Chem. Miner. 2001, 28, 1-8.

(46) Cattelan, M.; Markman, B.; Lucchini, G.; Das, P. K.; Vobornik, I.; Robinson, J. A.; Agnoli, S.; Granozzi, G. New Strategy for the Growth of Complex Heterostructures Based on Different 2D Materials. Chem. Mater. 2015, 27, 4105-4113.

(47) Nakano, M.; Wang, Y.; Kashiwabara, Y.; Matsuoka, H.; Iwasa, Y. Layer-by-Layer Epitaxial Growth of Scalable $\mathrm{WSe}_{2}$ on Sapphire by Molecular Beam Epitaxy. Nano Lett. 2017, 17, 5595-5599.

(48) Klein, A.; Tiefenbacher, S.; Eyert, V.; Pettenkofer, C.; Jaegermann, W. Electronic Band Structure of Single-Crystal and Single-Layer $\mathrm{WS}_{2}$ : Influence of Interlayer van der Waals Interactions. Phys. Rev. B 2001, 64, 205416.

(49) Zhang, X.; Choudhury, T. H.; Chubarov, M.; Xiang, Y.; Jariwala, B.; Zhang, F.; Alem, N.; Wang, G.-C.; Robinson, J. A.; Redwing, J. M. Diffusion-Controlled Epitaxy of Large Area Coalesced $\mathrm{WSe}_{2}$ Monolayers on Sapphire. Nano Lett. 2018, 18, 1049-1056. 
(50) Suenaga, K.; Ji, H. G.; Lin, Y.-C.; Vincent, T.; Maruyama, M.; Aji, A. S.; Shiratsuchi, Y.; Ding, D.; Kawahara, K.; Okada, S.; Panchal, V.; Kazkova, O.; Hibino, H.; Suenaga, K.; Ago, H. Surface-Mediated Aligned Growth of Monolayer $\mathrm{MoS}_{2}$ and in-Plane Heterostructures with Graphene on Sapphire. ACS Nano 2018, 12, 10032-10044.

(51) Lin, Y.-C.; Jariwala, B.; Bersch, B. M.; Xu, K.; Nie, Y.; Wang, B.; Eichfeld, S. M.; Zhang, X.; Choudhury, T. H.; Pan, Y.; Addou, R.; Smyth, C. M.; Li, J.; Zhang, K.; Haque, M. A.; Fölsch, S.; Feenstra, R. M.; Wallace, R. M.; Cho, K.; Fullerton-Shirey, S. K.; Redwing, J. M.; Robinson, J. A. Realizing Large-Scale, Electronic-Grade Two- Dimensional Semiconductors. ACS Nano 2018, 12, 965-975.

(52) Soares, E. A.; Van Hove, M. A.; Walters, C. F.; McCarty, K. F. Structure of the $\alpha-\mathrm{Al}_{2} \mathrm{O}_{3}(0001)$ Surface from Low-Energy Electron Diffraction: Al Termination and Evidence for Anomalously Large Thermal Vibrations. Phys. Rev. B 2002, 65, 195405.

(53) Walters, C. F.; McCarty, K. F.; Soares, E. A.; Van Hove, M. A. The Structure of the $\alpha-$ $\mathrm{Al}_{2} \mathrm{O}_{3}(0001)$ Surface from Low-Energy Electron Diffraction: Al Termination and Evidence for Large Thermal Vibrations. Surf. Sci. 2000, 464, L732-738. 


\section{Supporting Information}

\section{van der Waals Epitaxy of Continuous Thin Films of 2D}

Materials Using Atomic Layer Deposition in Low Temperature and Low Vacuum Conditions

Miika Mattinen ${ }^{* \dagger}$, Peter J. King ${ }^{\dagger \ddagger}$, Georgi Popov ${ }^{\dagger}$, Jani Hämäläinen ${ }^{\dagger \ddagger}$, Mikko J. Heikkilä, ${ }^{\dagger}$ Markku Leskelä, ${ }^{\dagger}$ Mikko Ritala ${ }^{* \dagger}$

${ }^{\dagger}$ Department of Chemistry, University of Helsinki, P.O. Box 55, FI-00014, Finland

\$Present address: Picosun Oy, Masalantie 365, FI-02430, Masala, Finland

\section{Contents}

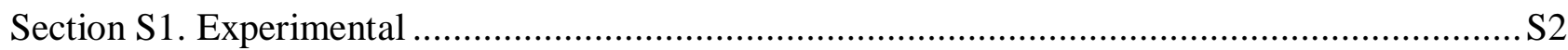

Section S2. Additional XRD characterization of $\mathrm{ZrS}_{2}$ films on mica......................................... 5

Section S3. Evidence for the $0,30,60$, and $90^{\circ}$ domains from the morphology of $\mathrm{SnS}_{2}$ films on mica

Section S4. Comparison of crystallite size of $\mathrm{SnS}_{2}$ films deposited on different substrates..... S6

Section S5. Epitaxial alignment of $\mathrm{HfS}_{2}, \mathrm{SnS}_{2}$, and $\mathrm{ZrS}_{2}$ films on mica S7

Section S6. Additional XRD characterization of $\mathrm{HfS}_{2}$ films on mica S9

Section S7. Additional XRD characterization of $\mathrm{SnS}_{2}$ films on mica S9

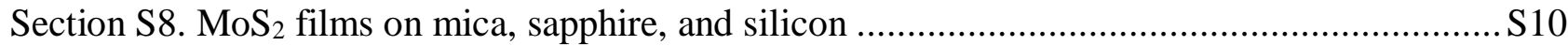

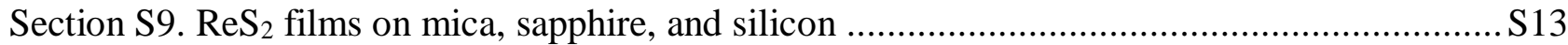

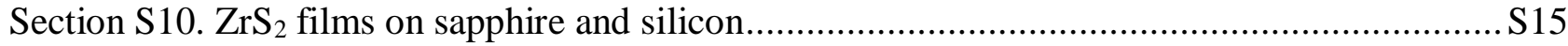

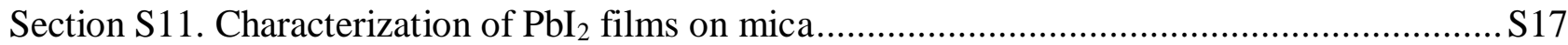

Section $\mathrm{S} 12$. Additional characterization of $\mathrm{PbI}_{2}$ films on sapphire ........................................ 18

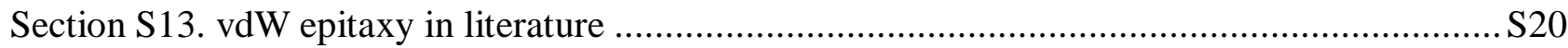

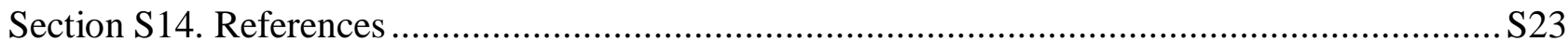




\section{Section S1. Experimental}

The studied films were deposited by ALD using previously reported processes (Table S1). In each case, a single film of a thickness specified in the table was selected for more detailed studies. We confirmed that the epitaxial growth was retained over a range of thicknesses using $\mathrm{SnS}_{2}$.

Table S1. Precursors, deposition conditions, and thicknesses of the studied films. The thicknesses were measured by XRR ( $\mathrm{HfS}_{2}, \mathrm{SnS}_{2}, \mathrm{ReS}_{2}$, and $\left.\mathrm{ZrS} \mathrm{S}_{2}\right)$ or EDS $\left(\mathrm{MoS}_{2}\right.$ and $\left.\mathrm{PbI}_{2}\right)$. The temperature of $270{ }^{\circ} \mathrm{C}$ used for $\mathrm{MoS}_{2}$ corresponds to the $300{ }^{\circ} \mathrm{C}$ reported in the original publication, where the temperature was measured in a different way.

\begin{tabular}{|c|c|c|c|c|}
\hline $\begin{array}{c}\text { Material } \\
\text { (Structure) }\end{array}$ & Precursors & Temperature $\left({ }^{\circ} \mathbf{C}\right)$ & Thickness (cycles) & Ref. \\
\hline $\mathrm{HfS}_{2}(\mathbf{1 T})$ & $\mathrm{HfCl}_{4}+\mathrm{H}_{2} \mathrm{~S}$ & 400 & $10 \mathrm{~nm}(1000)$ & 1 \\
\hline $\mathrm{MoS}_{2}(2 \mathrm{H})$ & $\mathrm{Mo}(\text { thd })_{3}+\mathrm{H}_{2} \mathrm{~S}$ & $\sim 270$ & $\sim 25 \mathrm{~nm}(10000)$ & 2 \\
\hline $\mathrm{PbI}_{2}(1 \mathrm{~T})$ & $\mathrm{Pb}(\mathrm{hmds})_{2}+\mathrm{SnI}_{4}$ & 75 & $\sim 20 \mathrm{~nm}(2000)$ & 3 \\
\hline $\mathrm{SnS}_{2}(1 \mathrm{~T})$ & $\mathrm{Sn}(\mathrm{OAc})_{4}+\mathrm{H}_{2} \mathrm{~S}$ & $\begin{array}{c}150+\text { anneal } \\
300 \text { (mica) or } \\
250 \text { (Si, sapphire) }\end{array}$ & $5 \mathrm{~nm}(400)$ & 4 \\
\hline $\operatorname{ReS}_{2}\left(1 T^{\prime}\right)$ & $\mathrm{ReCl}_{5}+\mathrm{H}_{2} \mathrm{~S}$ & $\begin{array}{l}250 \\
400\end{array}$ & $\begin{array}{l}17 \mathrm{~nm}(150) \\
8 \mathrm{~nm}(300)\end{array}$ & 5 \\
\hline $\mathrm{ZrS}_{2}(\mathbf{1 T})$ & $\mathrm{ZrCl}_{4}+\mathrm{H}_{2} \mathrm{~S}$ & 400 & $7 \mathrm{~nm}(1000)$ & 1 \\
\hline
\end{tabular}

The depositions were performed in a hot-wall cross-flow ALD reactor (ASM Microchemistry F120) operated under a $\mathrm{N}_{2}$ pressure of approximately 5 mbar. The metal precursors were evaporated from open glass boats inside the reactor at the following temperatures: $130{ }^{\circ} \mathrm{C}$ for $\mathrm{Sn}(\mathrm{OAc})_{4}$ (Alfa Aesar), $55^{\circ} \mathrm{C}$ for $\mathrm{Pb}$ (hmds) $)_{2}$ (hmds = 1,1,1,3,3,3-hexamethyldisilazane, synthesized in-house), $65^{\circ} \mathrm{C}$ for $\mathrm{SnI}_{4}$ (>99\%, Acros Organics), $115{ }^{\circ} \mathrm{C}$ for $\mathrm{Mo}(\text { thd })_{3}$ (thd = 2,2,6,6,-tetramethylheptane-3,5-dionate, synthesized in-house), $110{ }^{\circ} \mathrm{C}$ for $\mathrm{ReCl}_{5}$ (99.9\%, Strem), $125{ }^{\circ} \mathrm{C}$ for $\mathrm{HfCl}_{4}$ (99.99\%, Strem) and 130 ${ }^{\circ} \mathrm{C}$ for $\mathrm{ZrCl}_{4}$ (EpiValence). All the precursors are air and moisture sensitive and were handled in glove box under $\mathrm{N}_{2}$ until they were transferred into the ALD reactor to minimize the air exposure.

For the metal sulfide depositions, $\mathrm{H}_{2} \mathrm{~S}$ (Linde, 99.5\%) was supplied through needle and solenoid valves at a flow rate of $14 \mathrm{sccm}$. $\mathrm{HfSs}_{2}$ and $\mathrm{ZrS}_{2}$ are very sensitive towards oxidation and therefore gas purifiers were used for both $\mathrm{N}_{2}$ (SAES Microtorr MC1-902F, specified to remove $\mathrm{H}_{2} \mathrm{O}, \mathrm{H}_{2}, \mathrm{CO}_{2}$, $\mathrm{CO}$, and $\mathrm{O}_{2}$ to $<100 \mathrm{ppt}$, organic acids and refractory compounds to $<1 \mathrm{ppt}$, bases to $<5 \mathrm{ppt}$, and 
metals to $<1 \mathrm{ppb}$ ) and $\mathrm{H}_{2} \mathrm{~S}$ (SAES Microtorr MC1-302F, specified to remove $\mathrm{H}_{2} \mathrm{O}$ and metals to $<1$ $\mathrm{ppb})$. Additional pre-treatment of the reactor to remove impurities was also used for these materials as described before. ${ }^{1} \mathrm{~Pb}(\mathrm{hmds})_{2}$ is very reactive towards oxygen-containing impurities, so a nitrogen purifier was used (Millipore Entegris Mykrolis WPMV200SI, specified to remove $\mathrm{O}_{2}$ to $<1 \mathrm{ppb}$ and $\mathrm{H}_{2} \mathrm{O}$ to $<1 \mathrm{ppb}$ ). In each case, the pulse times were long enough to saturate the surface reactions as studied in the original publications.

The films were deposited on two substrates commonly used for vdW epitaxy: c-plane sapphire ( $\alpha$ $\mathrm{Al}_{2} \mathrm{O}_{3}, 2$ " wafers, c-plane off to M-plane by $0.2 \pm 0.1^{\circ}$, double-side polished, University Wafer) and muscovite mica $\left(\mathrm{KAl}_{2}\left(\mathrm{Si}_{3} \mathrm{Al}\right) \mathrm{O}_{10}(\mathrm{OH})_{2}\right.$, Nano-Tec, $\mathrm{V} 1$ grade, $2.5 \times 5$ or $5 \times 5 \mathrm{~cm}^{2}$ sheets or $15 \mathrm{~mm}$ disks, 0.15-0.21 mm thickness). The sapphire wafers were rinsed with ethanol, acetone, and isopropanol and blown dry using $\mathrm{N}_{2}$. The wafers were then annealed in air at $1000{ }^{\circ} \mathrm{C}$ for $2 \mathrm{~h}$ in a muffle oven to create atomically flat terraces separated by atomic steps. ${ }^{6,7}$ The muscovite mica substrates were cleaved using a double-edge razor blade to create a clean (001) surface immediately before loading into the reactor. ${ }^{8}$ Care should be taken in cleaving mica into as flat surfaces as possible because highly stepped or bent mica sheets turned out to be very difficult to align for in-plane XRD measurements. Most XRD measurements were performed on $15 \mathrm{~mm}$ mica disks as the larger sheets were usually not flat enough for successful XRD measurements.

Film morphology was studied by tapping mode atomic force microscopy (AFM, Veeco Multimode V) in air using silicon probes (Bruker) with a nominal tip radius of less than $10 \mathrm{~nm}$. The images were flattened to remove artefacts caused by sample tilt and scanner nonlinearity. Film roughness was calculated as a root-mean-square value $\left(\mathrm{R}_{\mathrm{q}}\right)$. Scanning electron microscopy (SEM, Hitachi S-4800) was also used to study the morphology of selected films.

Film thicknesses were mostly measured by X-ray reflectivity (XRR) using a Rigaku SmartLab diffractometer. Thicknesses of the rougher $\mathrm{MoS}_{2}$ and $\mathrm{PbI}_{2}$ films that could not be measured by XRR were measured by energy-dispersive X-ray spectrometry (EDS) using an Oxford INCA 350 spectrometer connected to a Hitachi S-4800 SEM. The film thicknesses were calculated from the measured $\mathrm{k}$ ratios (Mo $\mathrm{L} \alpha, \mathrm{S} \mathrm{K} \alpha, \mathrm{I} \mathrm{L} \alpha$, and $\mathrm{Pb} \mathrm{M} \alpha$ ) using a GMRFilm software. ${ }^{9}$ Smooth and uniform films and bulk densities ${ }^{10}$ of $5.06 \mathrm{~g} / \mathrm{cm}^{3}\left(\mathrm{MoS}_{2}\right)$ and $6.10 \mathrm{~g} / \mathrm{cm}^{3}\left(\mathrm{PbI}_{2}\right)$ were assumed.

The crystallinity, preferred orientations, and epitaxial relationships of the films were studied by Xray diffraction using a Rigaku SmartLab diffractometer equipped with a $\mathrm{Cu} \mathrm{X}$-ray tube and an X-ray mirror producing a parallel beam. The beam contained mainly $\mathrm{Cu} K \alpha$ radiation $(\lambda \approx 1.54 \AA$, consisting of $\mathrm{K} \alpha 1$ at $1.5406 \AA$ and $\mathrm{K} \alpha 2$ at $1.5443 \AA) . \mathrm{Cu} \mathrm{K} \beta(\lambda=1.39 \AA)$ and $\mathrm{W} \mathrm{L} \alpha(\lambda=1.48 \AA)$ lines were also 
present, which caused additional peaks in the diffractograms. $\mathrm{Cu} \mathrm{K} \beta$ radiation is obviously created together with the $\mathrm{Cu} \mathrm{K \alpha}$ radiation at the copper anode of the $\mathrm{X}$-ray tube, whereas $\mathrm{W} \mathrm{L} \alpha$ radiation is due to tungsten evaporated from the cathode to the anode of the tube.

Out-of-plane texture was initially examined using conventional grazing incidence $\left(2 \theta, \omega\right.$ fixed to $\left.1^{\circ}\right)$ and $\theta-2 \theta$ measurements. Additionally, rocking curve ( $\omega$ scan) measurements were performed on the (0001) or (0002) reflections of the films to quantify the out-of-plane texture. The instrumental broadening in the rocking curve measurements was approximately $0.05^{\circ}$. Epitaxial relationships between the films and the substrates were mainly explored by in-plane measurements using the inplane arm of the diffractometer. For the in-plane measurements, $\omega$ and $2 \theta$ were both fixed to $0.3^{\circ}$ while either the $2 \theta \chi$ or $\phi$ axes were scanned. The $2 \theta \chi$ scans were mainly used for the initial screening and to optimize the positions of the in-plane reflections. The $\phi$ scans with $2 \theta \chi$ fixed to a known substrate or film reflection were used to extract the epitaxial relationships between the film and the substrate. The $\phi$ scans of the substrate reflections were used to define $0{ }^{\circ} \phi$ to correspond to the [100] and $[\overline{1} 100]$ directions of mica and sapphire, respectively. Background correction was applied for the samples that had uneven background resulting from their physical shapes.

The domain (crystallite) size was estimated using Scherrer equation, which assumes that peak broadening results from a limited crystallite size. To obtain an estimate on the in-plane crystallite size, in-plane XRD $2 \theta \chi$ scans of $(10 \overline{1} 0)$ and $(11 \overline{2} 0) M_{2}$ peaks were used. For the epitaxial films on mica, $\varphi$ was chosen such that it corresponded to the $0 / 60^{\circ}$ domains. Instrumental broadening measured from a silicon standard was approximately $0.42-0.43^{\circ}$ in the $2 \theta$ angles of interest.

For the $\mathrm{PbI}_{2}$ film on sapphire, in-plane pole figure measurements were also used to simultaneously extract information on both the out-of-plane and in-plane orientations of the film. $1^{\circ}$ steps were used in both $\alpha$ and $\beta$ directions. The incident slits used to limit the beam size were 10 and $1 \mathrm{~mm}$ horizontally and vertically. In these measurements, the diffraction angle (20B) was fixed to $25.95^{\circ}$, which corresponds to the $(10 \overline{1} 1)$ reflection of $\mathrm{PbI}_{2}$ and is close enough to the $(01 \overline{1} 2)$ reflection of sapphire at $25.56^{\circ}$ to simultaneously observe both reflections. In the in-plane pole figure measurements, the $\alpha$ axis is controlled with a combination of the $2 \theta$ and the $2 \theta \chi$ (in-plane arm) axes, while $\beta$ is scanned by simply rotating the sample using the $\phi$ axis. More details on the in-plane and in-plane pole figure measurements can be found in references ${ }^{11,12}$. Here, $\alpha=0$ and $\alpha=90^{\circ}$ were defined to correspond to the edge and the center of the pole figure, in other words planes perpendicular and parallel to the substrate surface, respectively. 
VESTA software ${ }^{13}$ was used to visualize the structures of the films and the substrates.

Section S2. Additional XRD characterization of $\mathrm{ZrS}_{2}$ films on mica

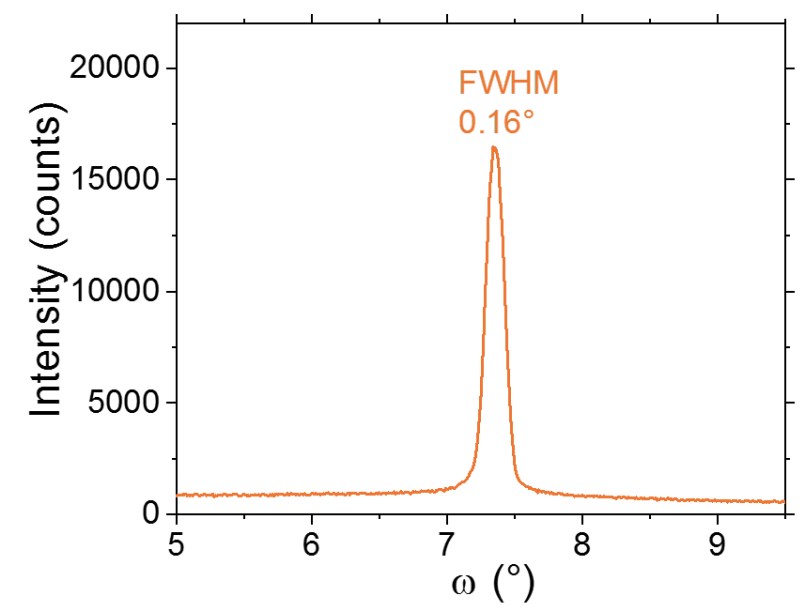

Figure S1. Rocking curve of the (0001) reflection ( $\omega$ scan, $14.7^{\circ} 2 \theta$ ) of a $\mathrm{ZrS}_{2}$ film deposited on mica using 1000 ALD cycles at $400{ }^{\circ} \mathrm{C}$.

Section S3. Evidence for the 0, 30, 60, and $90^{\circ}$ domains from the morphology of $\mathrm{SnS}_{2}$ films on mica
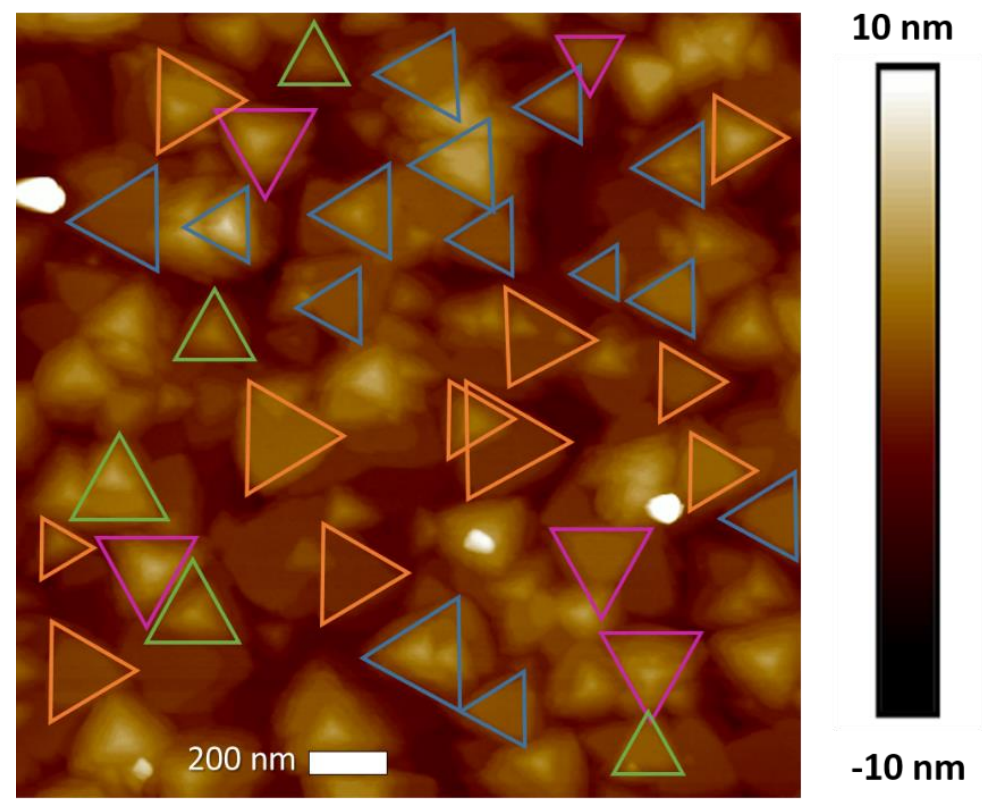

Figure S2. AFM image of a $\mathrm{SnS}_{2}$ film deposited on mica under conditions favoring island growth (500 ALD cycles at $175^{\circ} \mathrm{C}$, no annealing). The triangles of four different colors highlight the four preferred in-plane orientations. Misoriented and even randomly oriented domains are also evident. 
Section S4. Comparison of crystallite size of $\mathrm{SnS}_{2}$ films deposited on different substrates

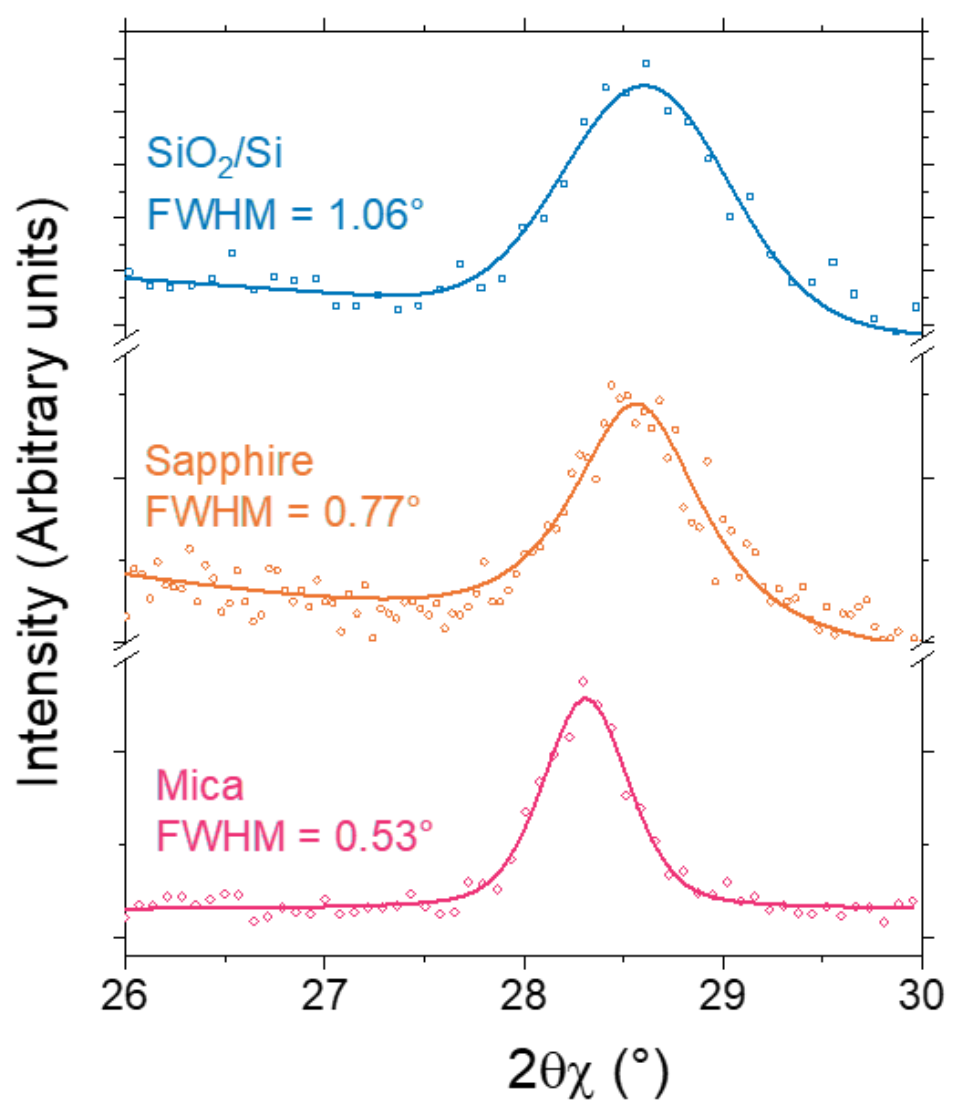

Figure S3. In-plane X-ray diffractograms ( $2 \theta \chi$ scans) of $5 \mathrm{~nm}$ thick $\mathrm{SnS}_{2}$ films deposited on different substrates (deposition at $150{ }^{\circ} \mathrm{C}$ followed by $\mathrm{H}_{2} \mathrm{~S} / \mathrm{N}_{2}$ annealing at 250 or $300{ }^{\circ} \mathrm{C}$ ). The open symbols and solid lines represent data and fits to the data, respectively. The shown FWHMs of the fitted $(10 \overline{1} 0) \mathrm{SnS}_{2}$ peaks were used to estimate the domain size using Scherrer equation. The peak on mica is closest to the reference position of the $(10 \overline{1} 0) \mathrm{SnS}_{2}$ reflection of $28.2^{\circ}$, which implies that the film on mica is the least strained. The film on mica was measured at a $\varphi$ angle corresponding to $0 / 60^{\circ}$ domains, whereas the films on $\mathrm{SiO}_{2} / \mathrm{Si}$ and sapphire were measured at a random $\varphi$ angle. 
Section S5. Epitaxial alignment of $\mathrm{HfS}_{2}, \mathrm{SnS}_{2}$, and $\mathrm{ZrS}_{2}$ films on mica

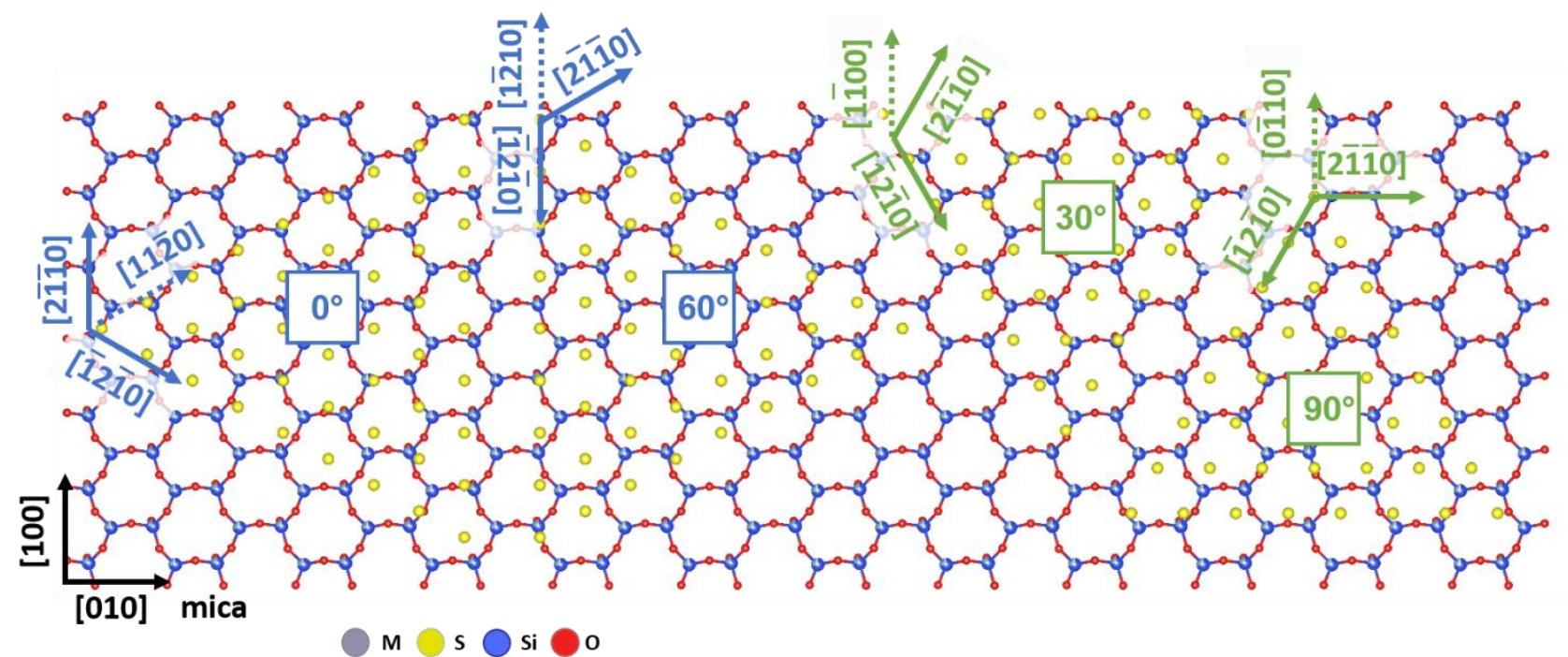

Figure S4. Schematic of only the bottom sulfur layer of the possible $\mathrm{MS}_{2}(\mathrm{M}=\mathrm{Hf}, \mathrm{Sn}, \mathrm{Zr})$ domains on mica. The angle refers to a clockwise rotation of the $\mathrm{MS}_{2}$ unit cell. For clarity, only the bottom sulfur layer of an $\mathrm{MS}_{2}$ layer is drawn.

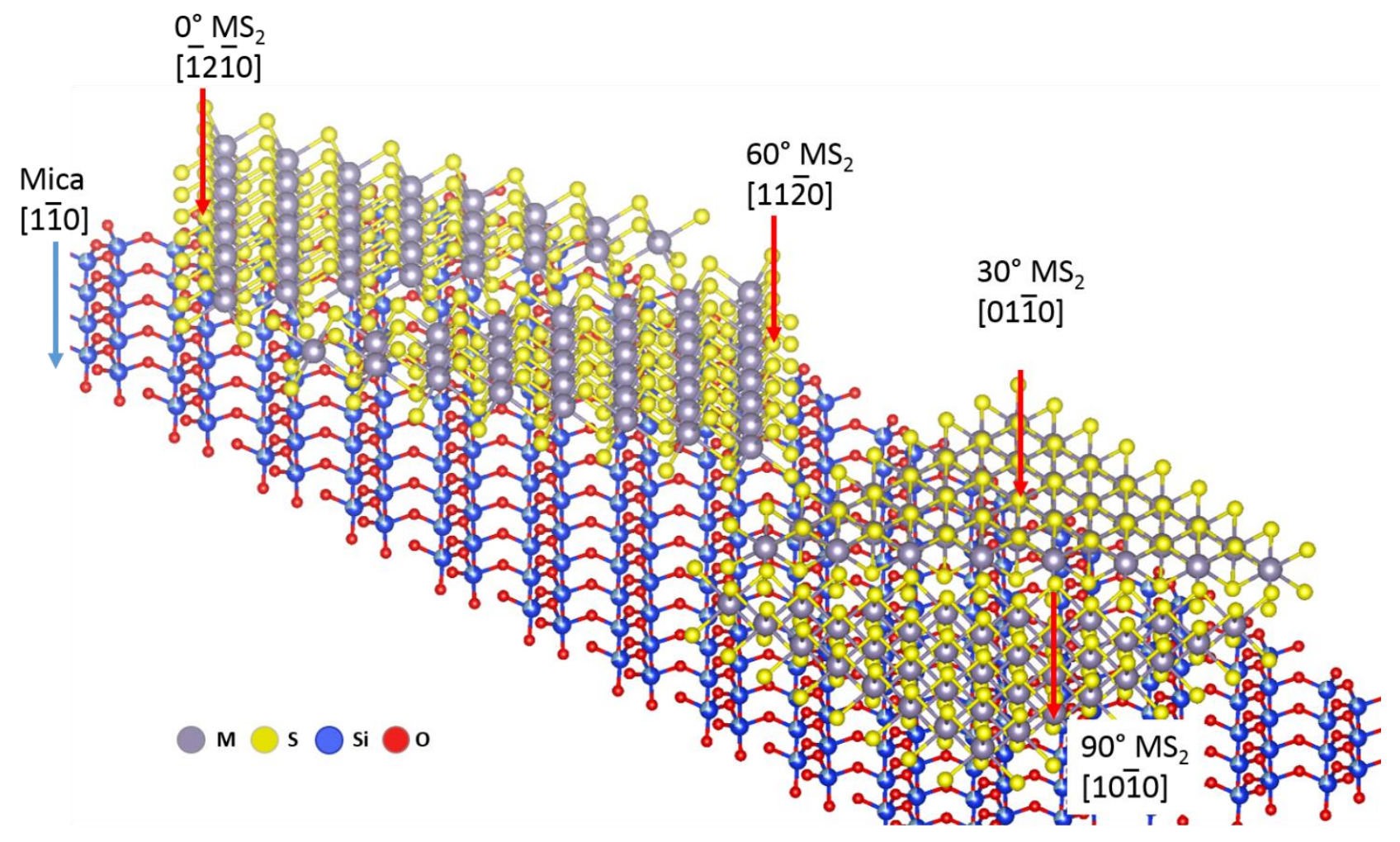

Figure S5. Schematic tilted view of the different $\mathrm{MS}_{2}(\mathrm{M}=\mathrm{Hf}, \mathrm{Sn}, \mathrm{Zr})$ domains on mica (for clarity, only one $\mathrm{MS}_{2}$ layer is drawn). The sulfur rows (the most densely packed rows (S-S 3.64-3.66 $\AA$ ) run in the $\langle 1 \overline{2} 10>$ and $<11 \overline{2} 0>$ directions and less densely packed rows (S-S 6.30-6.33 $\AA$ ) along the $\langle 0 \overline{1} 10>$ and $<10 \overline{1} 0>$ directions) aligned parallel to the silicon-oxygen zig-zag rows in mica ( $<100>,<110>$, and $<1 \overline{1} 0>$ directions) are indicated. The sulfur rows have six-fold rotational symmetry and the silicon-oxygen rows with slight variations in atomic positions also occur every $60^{\circ}$. 

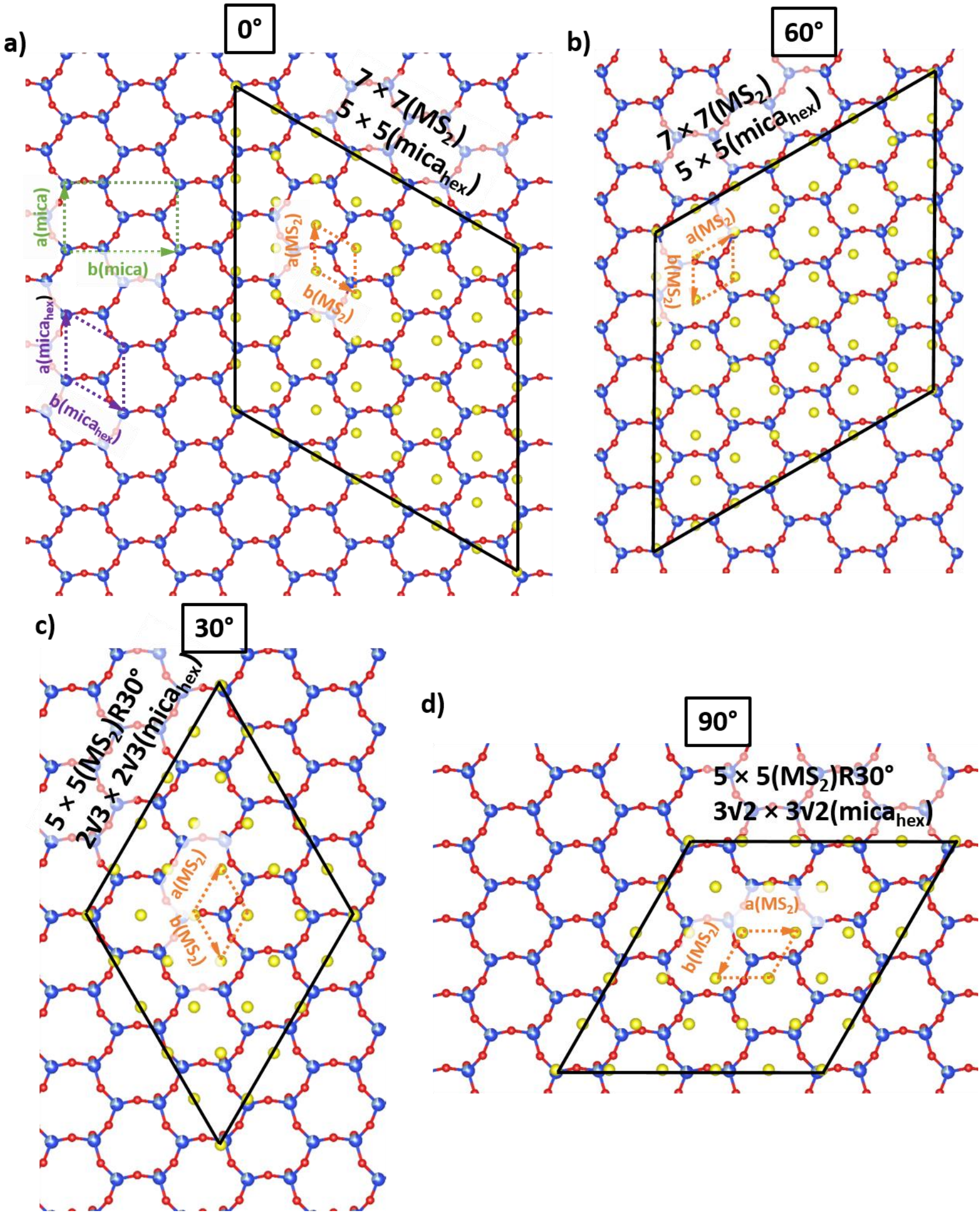

Figure S6. Schematic of possible coincidence site lattices (CSLs) for a) $0^{\circ}$, b) $60^{\circ}$, c) $30^{\circ}$, and d) $90^{\circ}$ $\mathrm{MS}_{2}$ domains on mica. Instead of the rectangular unit cell of (001)mica surface (green), a hexagonal cell (violet) is used for the suggested CSLs although the mica surface is not strictly hexagonal due to small variations in atom positions. For clarity, only the bottom sulfur layer is drawn on the top mica surface. 
Section S6. Additional XRD characterization of $\mathrm{HfS}_{2}$ films on mica
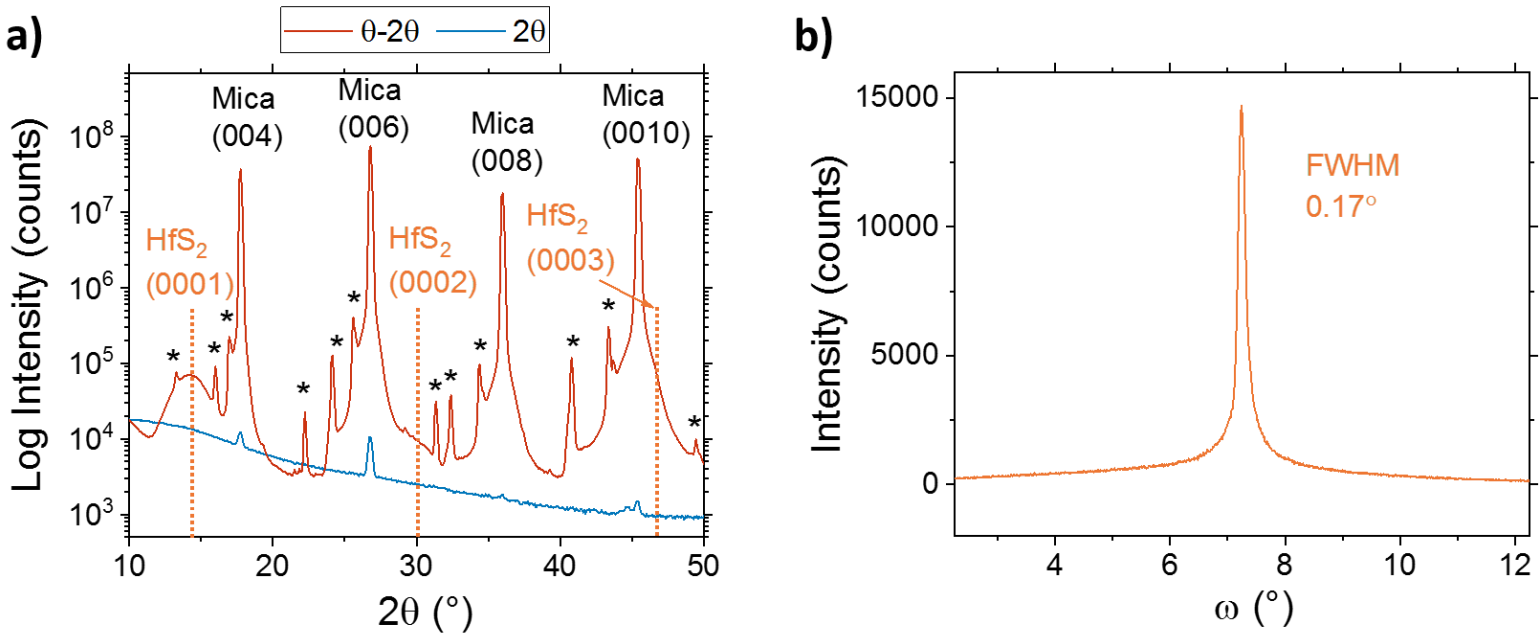

Figure S7. a) $\theta-2 \theta$ (red) and grazing incidence $(2 \theta$, blue) X-ray diffractograms and b) rocking curve of the (0001) reflection $\left(14.5^{\circ} 2 \theta\right)$ of a $\mathrm{HfS}_{2}$ film deposited on mica using 1000 ALD cycles at 400 ${ }^{\circ} \mathrm{C}$. In a) the $\mathrm{HfS}_{2}$ and substrate reflections are marked in orange and black. Asterisks mark substrate peaks originating from $\mathrm{W} \mathrm{L} \alpha$ and $\mathrm{Cu} \mathrm{K} \beta$ radiation.

\section{Section S7. Additional XRD characterization of $\mathrm{SnS}_{2}$ films on mica}
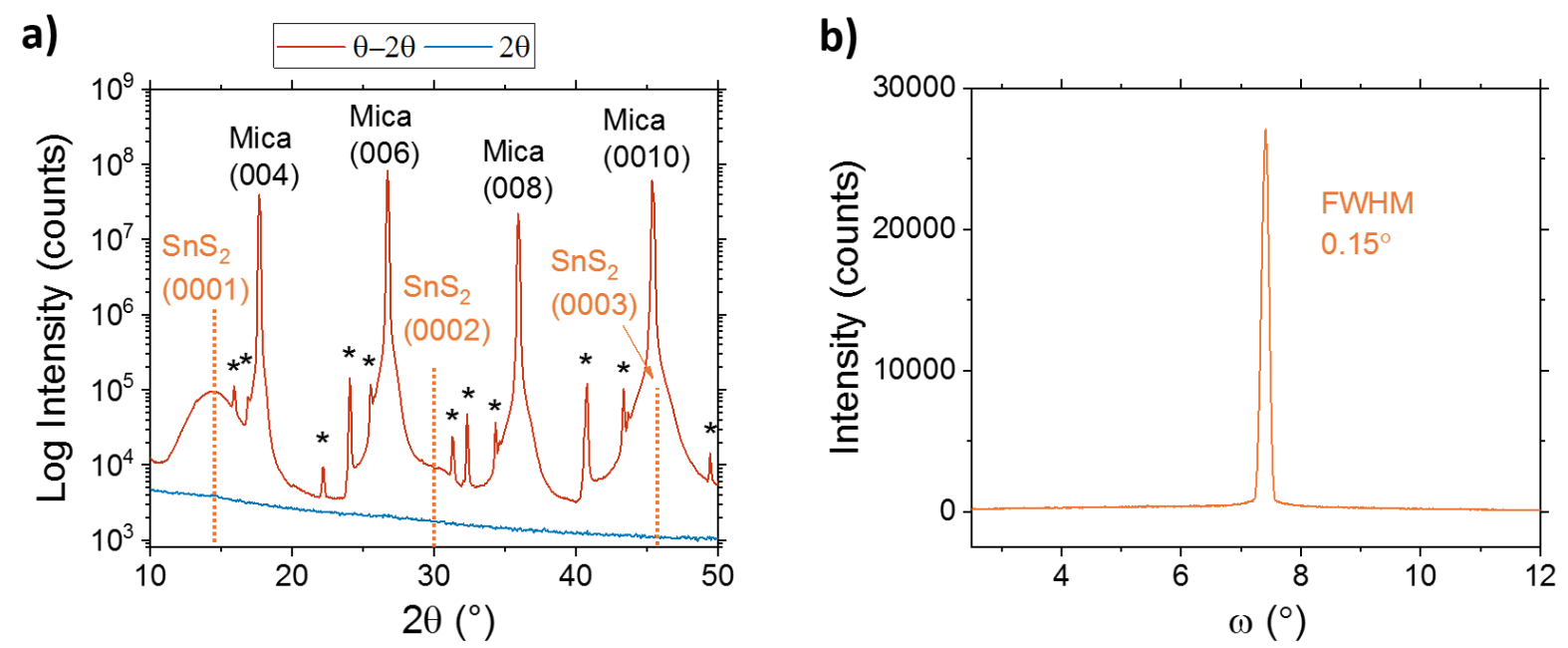

Figure S8. a) $\theta-2 \theta$ (red) and grazing incidence $(2 \theta$, blue) X-ray diffractograms and b) rocking curve of the (0001) reflection $\left(14.8^{\circ} 2 \theta\right)$ of a $\mathrm{SnS}_{2}$ film deposited on mica using 250 ALD cycles at 150 ${ }^{\circ} \mathrm{C}$ followed by $\mathrm{H}_{2} \mathrm{~S} / \mathrm{N}_{2}$ annealing at $300{ }^{\circ} \mathrm{C}$. In a) the $\mathrm{SnS}_{2}$ and substrate reflections are marked in orange and black. Asterisks mark substrate peaks originating from $\mathrm{W} L \alpha$ and $\mathrm{Cu} K \beta$ radiation. 
Section S8. $\mathrm{MoS}_{2}$ films on mica, sapphire, and silicon

a)

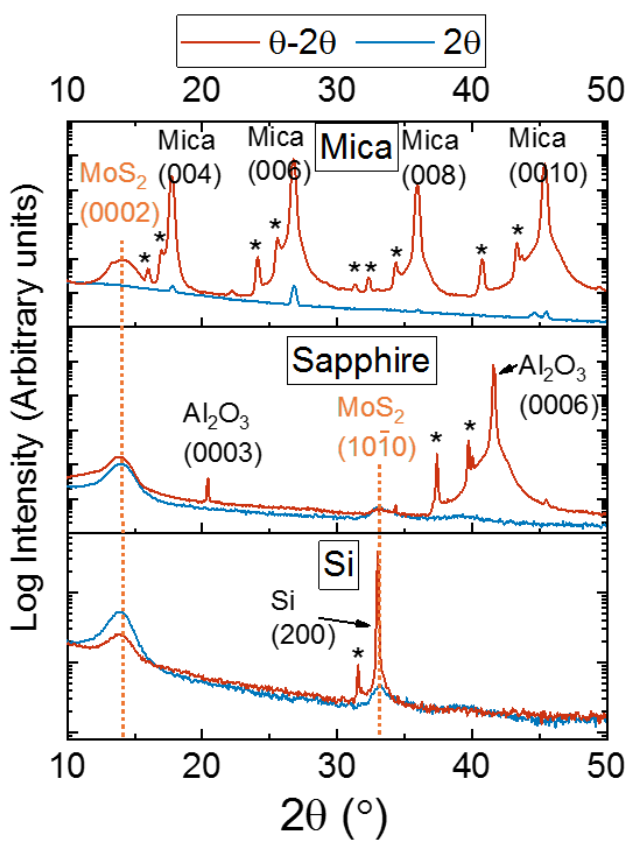

b)

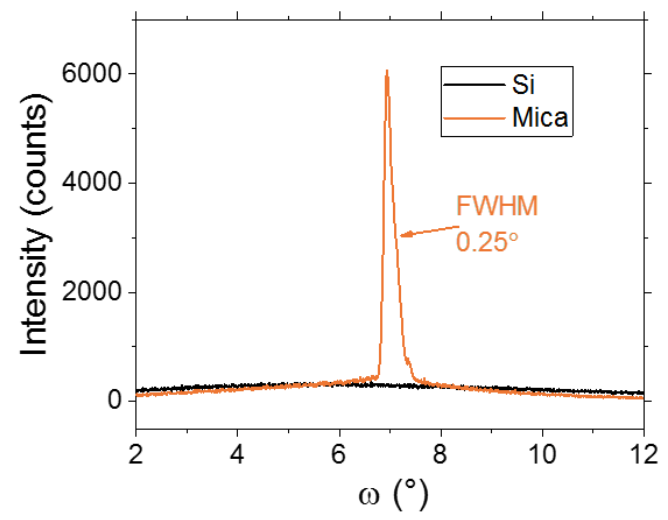

Figure S9. a) $\theta-2 \theta$ (red) and grazing incidence $(2 \theta$, blue) X-ray diffractograms and b) rocking curve of the (0001) reflection (13.9 ${ }^{\circ} 2 \theta$ ) of a $\mathrm{MoS}_{2}$ film deposited on different substrates using 10000 ALD cycles at $300{ }^{\circ} \mathrm{C}$. In a) the $\mathrm{MoS}_{2}$ and substrate reflections are marked in orange and black. Asterisks mark substrate peaks originating from $\mathrm{W} L \alpha$ and $\mathrm{Cu} K \beta$ radiation. Strong (0001) out-of-plane texture is evident on mica with only weak texturing observed on sapphire and silicon.
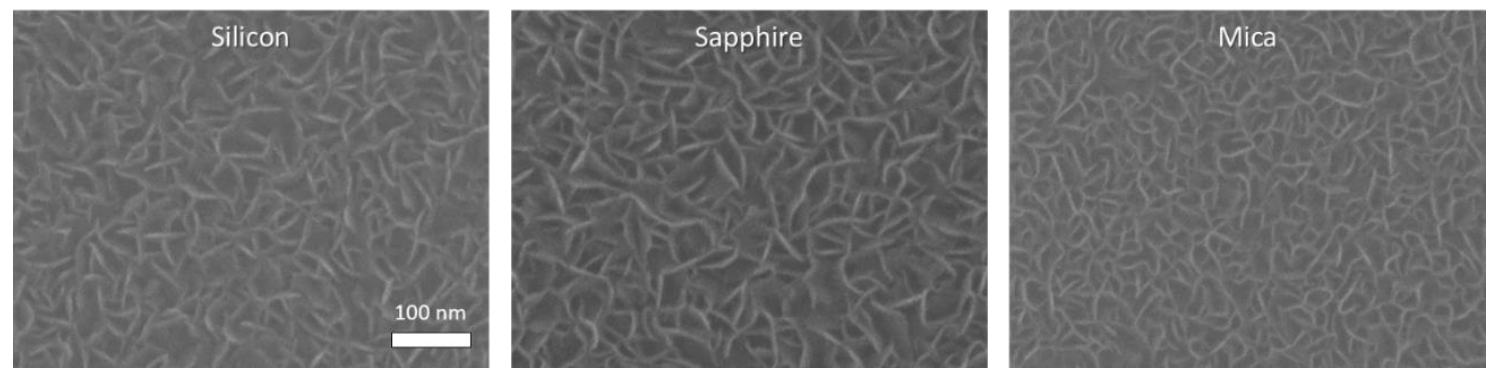

Figure S10. SEM images of $\mathrm{MoS}_{2}$ films grown on different substrates using 10000 ALD cycles at $300{ }^{\circ} \mathrm{C}$.
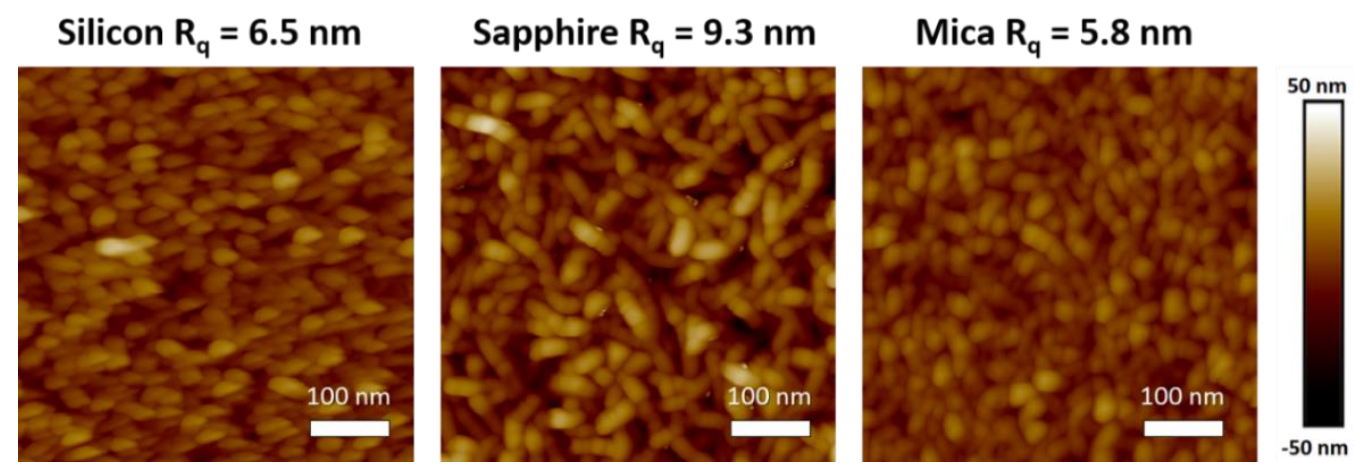

Figure S11. AFM images and roughnesses $\left(\mathrm{R}_{\mathrm{q}}\right)$ of $\mathrm{MoS}_{2}$ films deposited on different substrates using 10000 ALD cycles at $300{ }^{\circ} \mathrm{C}$. The films are relatively rough in line with the SEM images. 
a)

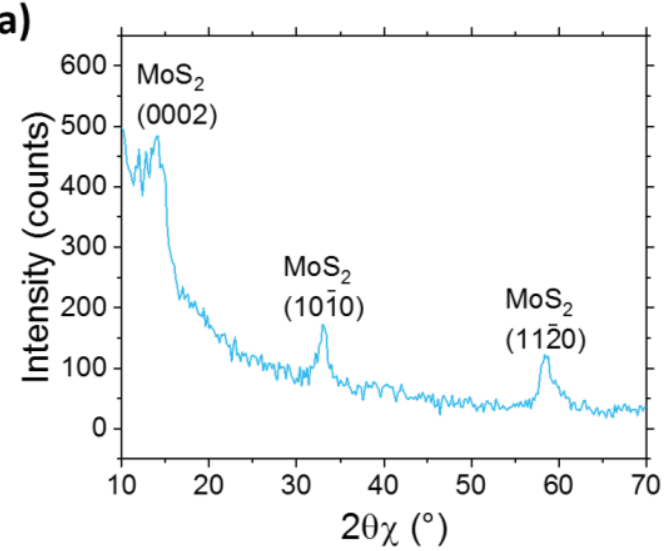

b)

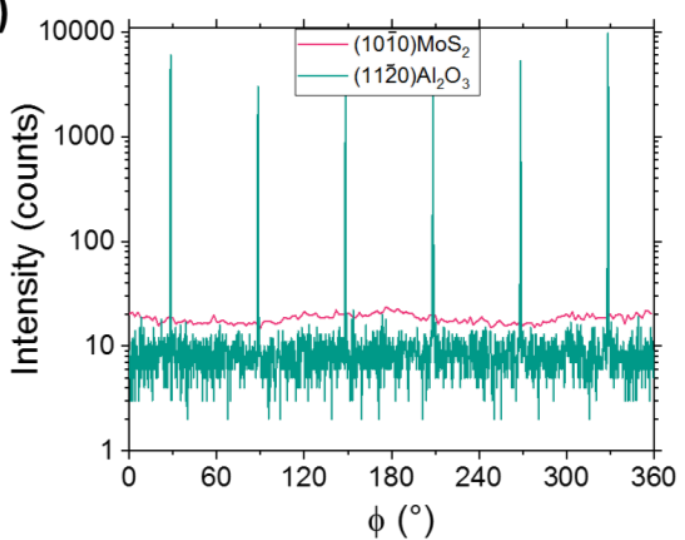

Figure S12. a) In-plane $2 \theta \chi$ and b) $\phi$ scans of a $\mathrm{MoS}_{2}$ film deposited on sapphire using 10000 ALD cycles at $300{ }^{\circ} \mathrm{C}$. The $\phi$ scans of the $(10 \overline{1} 0) \mathrm{MoS}_{2}$ and $(11 \overline{2} 0) \mathrm{Al}_{2} \mathrm{O}_{3}$ reflections were measured with $2 \theta \chi$ fixed to 33.1 and $37.75^{\circ}$. The observation of several reflections in the $2 \theta \chi$ scan and lack of peaks in the $\phi$ scan shows the $\mathrm{MoS}_{2}$ film to be non-epitaxial on sapphire.

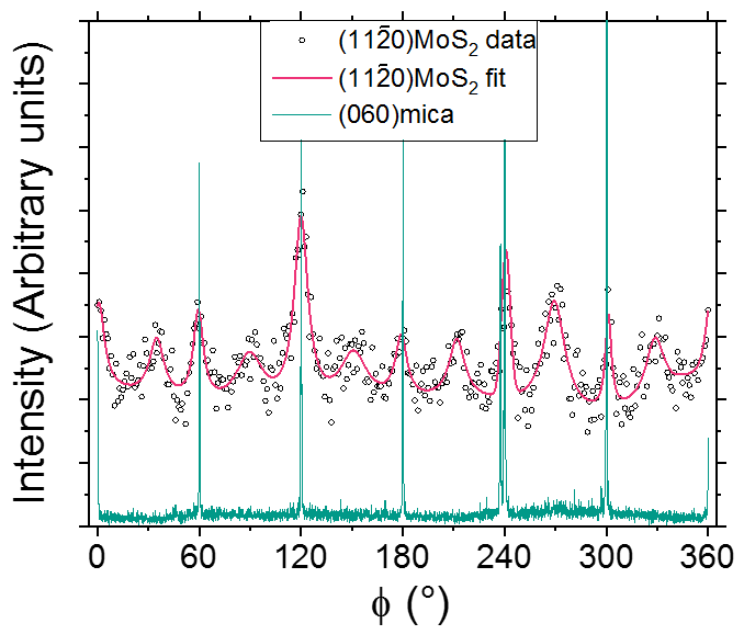

Figure S13. In-plane $\phi$ scans of $(11 \overline{2} 0) \mathrm{MoS}_{2}\left(58.3^{\circ} 2 \theta \chi\right)$ and (060)mica $\left(61.8^{\circ} 2 \theta \chi\right)$ reflections of a $\mathrm{MoS}_{2}$ film deposited on mica using 10000 ALD cycles at $300{ }^{\circ} \mathrm{C}$ showing at least partial epitaxial alignment. The $(11 \overline{2} 0)$ reflection was chosen over $(10 \overline{1} 0)$ due to the greater intensity of the former.

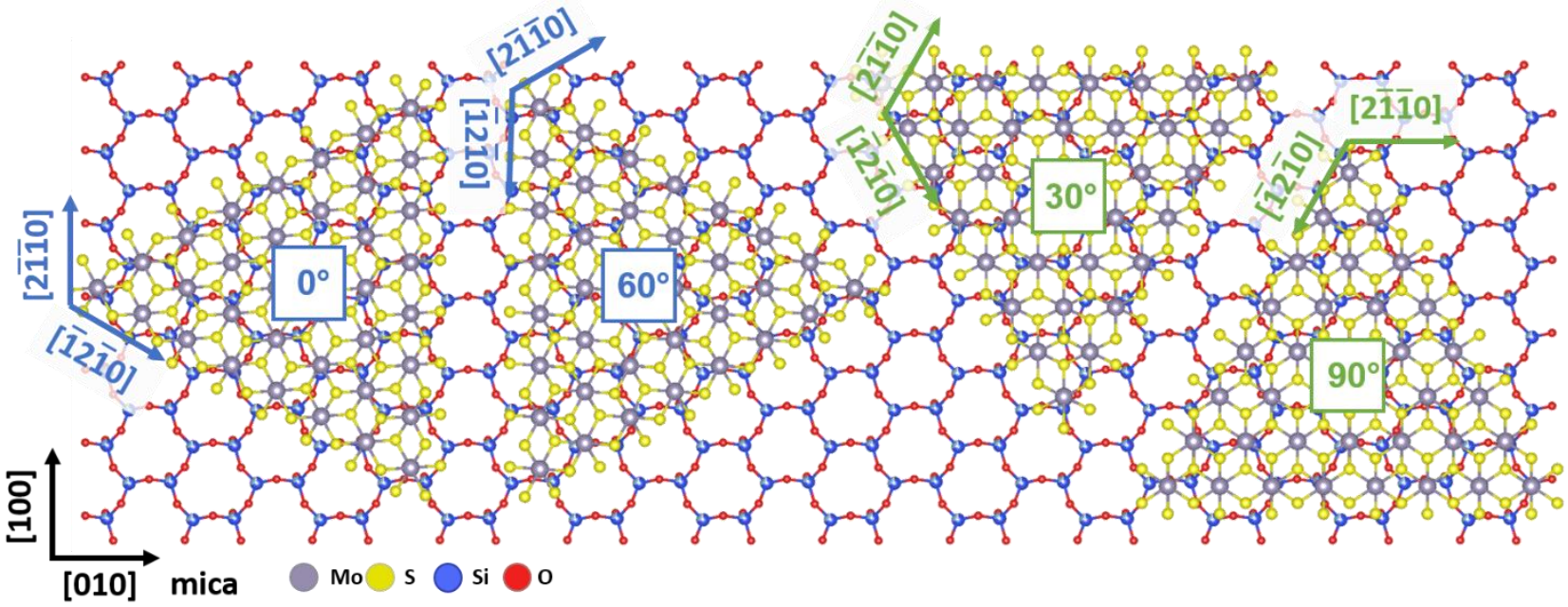

Figure S14. Schematic of the possible $\mathrm{MoS}_{2}$ domains on mica (only one $\mathrm{MoS}_{2}$ layer drawn for clarity) 


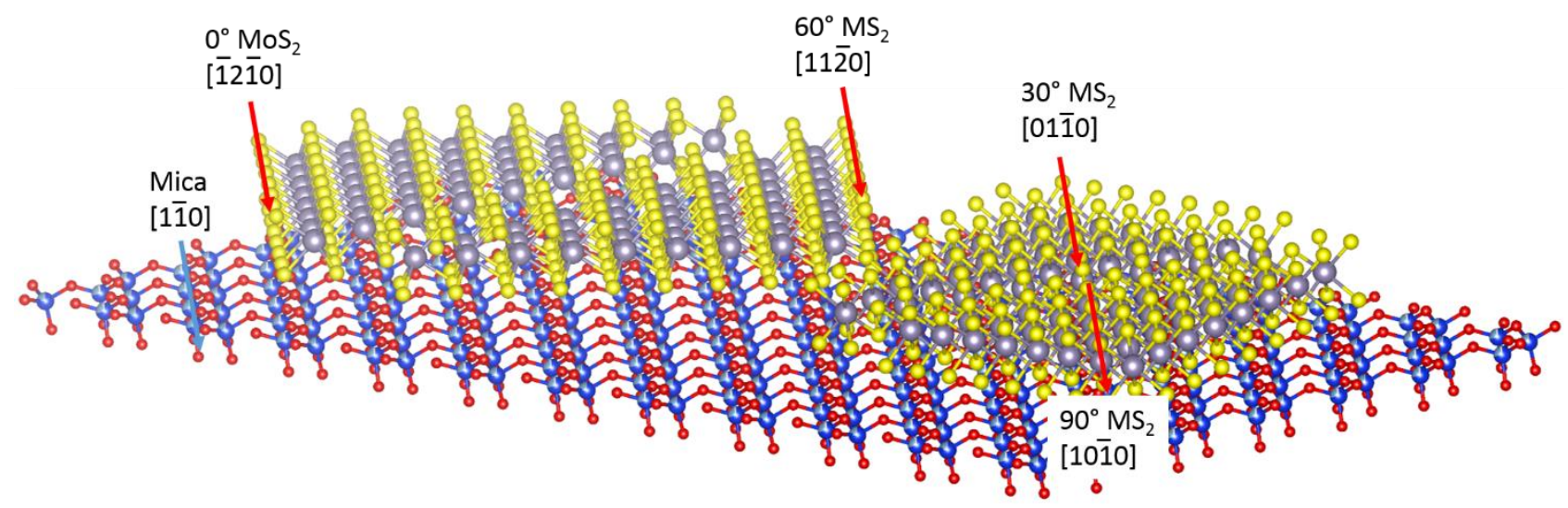

Figure S15. Schematic tilted view of the different $\mathrm{MoS}_{2}$ domains on mica. The sulfur rows aligned parallel to the zig-zig silicon-oxygen rows in mica are indicated. The sulfur rows have six-fold rotational symmetry and the silicon-oxygen rows with slight variations in atomic positions also occur every $60^{\circ}$. The tilted view highlights the fact that in the $2 \mathrm{H}$ structure the atoms in the top and the bottom sulfur layers are aligned on top of each other, which is in contrast to the otherwise very similar $1 \mathrm{~T}$ structure of $\mathrm{HfS}_{2}, \mathrm{SnS}_{2}$, and $\mathrm{ZrS}_{2}$. For clarity, only one $\mathrm{MoS}_{2}$ layer is drawn.

a)

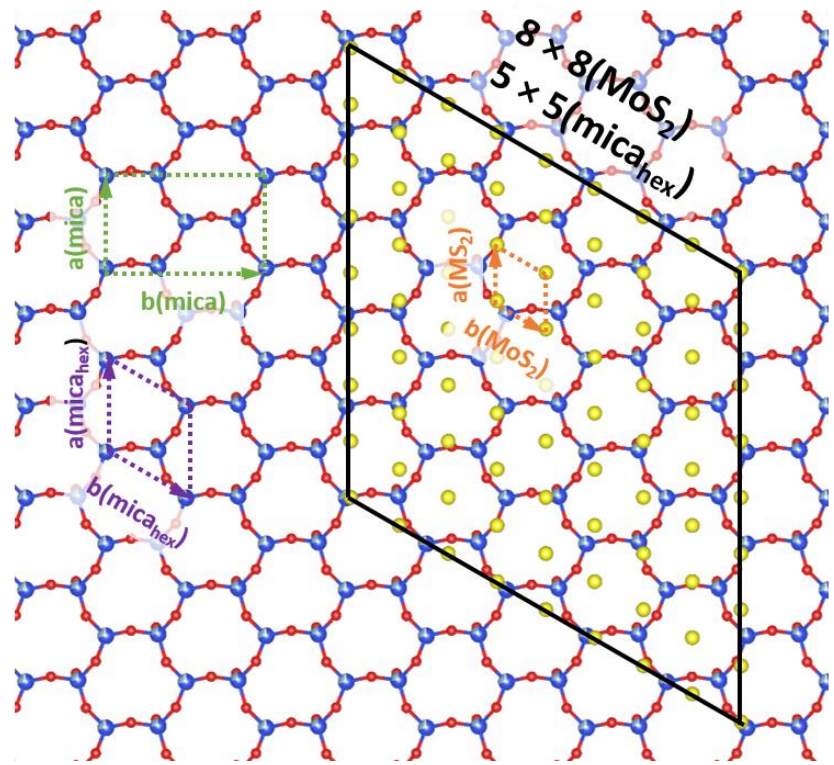

b)

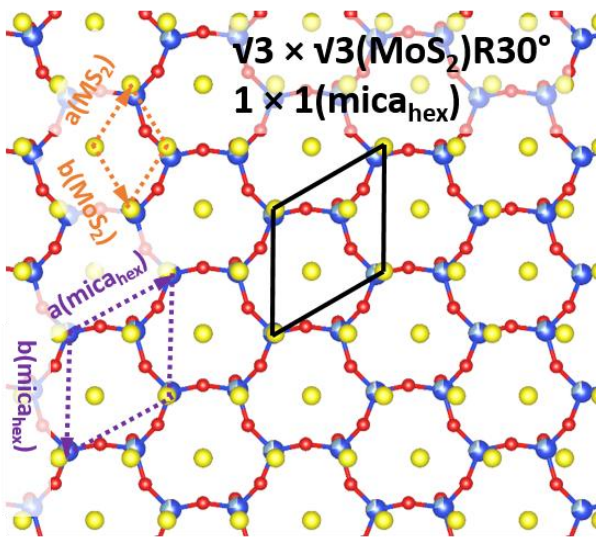

Figure S16. Schematic of possible CSLs for a) $0^{\circ}$ and b) $30^{\circ} \mathrm{MoS}_{2}$ domains on mica. Similar CSLs can be constructed for the possible 60 and $90^{\circ}$ domains. Instead of the rectangular unit cell of (001)mica surface (green), a hexagonal cell (violet) is used for the suggested CSLs although the mica surface is not strictly hexagonal due to small variations in atom positions. For clarity, only the bottom sulfur layer is shown. 


\section{Section $\mathrm{S} 9 . \mathrm{ReS}_{2}$ films on mica, sapphire, and silicon}

$\mathrm{ReS}_{2}$ films were grown on silicon, sapphire, and mica substrates at two deposition temperatures, 250 and $400{ }^{\circ} \mathrm{C}$. Strong (001) texture, a prerequisite for epitaxy, was only observed for the film grown on mica at $250{ }^{\circ} \mathrm{C}$ (Figures S17 and S18). Much higher diffraction intensities were observed for the films grown at $400{ }^{\circ} \mathrm{C}$, even though they were thinner, which suggests increased crystallinity (crystallite size) with increasing deposition temperature. The $\mathrm{ReS}_{2}$ films deposited at $400{ }^{\circ} \mathrm{C}$ were also rough due to the presence of some flakes oriented away from the substrate (Figure S19).

Characterization of the possible epitaxy of $\mathrm{ReS}_{2}$ is more complicated than the other materials studied in this work due to the triclinic structure of $\operatorname{ReS}_{2}$ (space group $P \overline{1}$, JCPDS-ICDD PDF 24-922) with all the unit cell angles differing from $90^{\circ}$. Thus, strictly in-plane reflections (planes perpendicular to the (001) plane) of reasonable intensity could not be found. Nevertheless, several in-plane pole figure measurements and $\phi$ scans on asymmetric reflections including (100) and (102) confirmed the nonepitaxial nature of the $\mathrm{ReS}_{2}$ films grown on all of the tested substrates.

a)

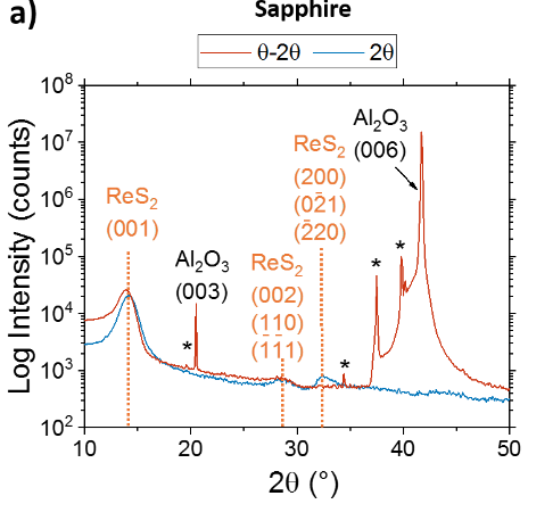

b)

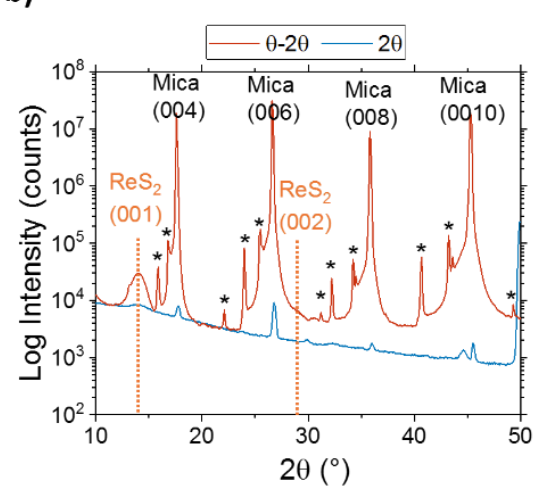

c)

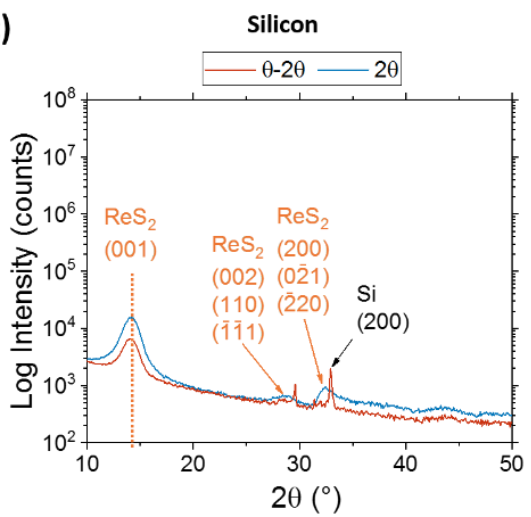

Figure S17. $\theta-2 \theta$ (red) and grazing incidence $\left(2 \theta\right.$, blue) $\mathrm{X}$-ray diffractograms of $\mathrm{ReS}_{2}$ films deposited on a) sapphire, b) mica, and c) silicon using 150 ALD cycles at $250{ }^{\circ} \mathrm{C}$. The $\mathrm{ReS}_{2}$ and substrate reflections are marked in orange and black. Asterisks mark peaks originating from $\mathrm{W} L \alpha$ and $\mathrm{Cu} K \beta$ radiation. 

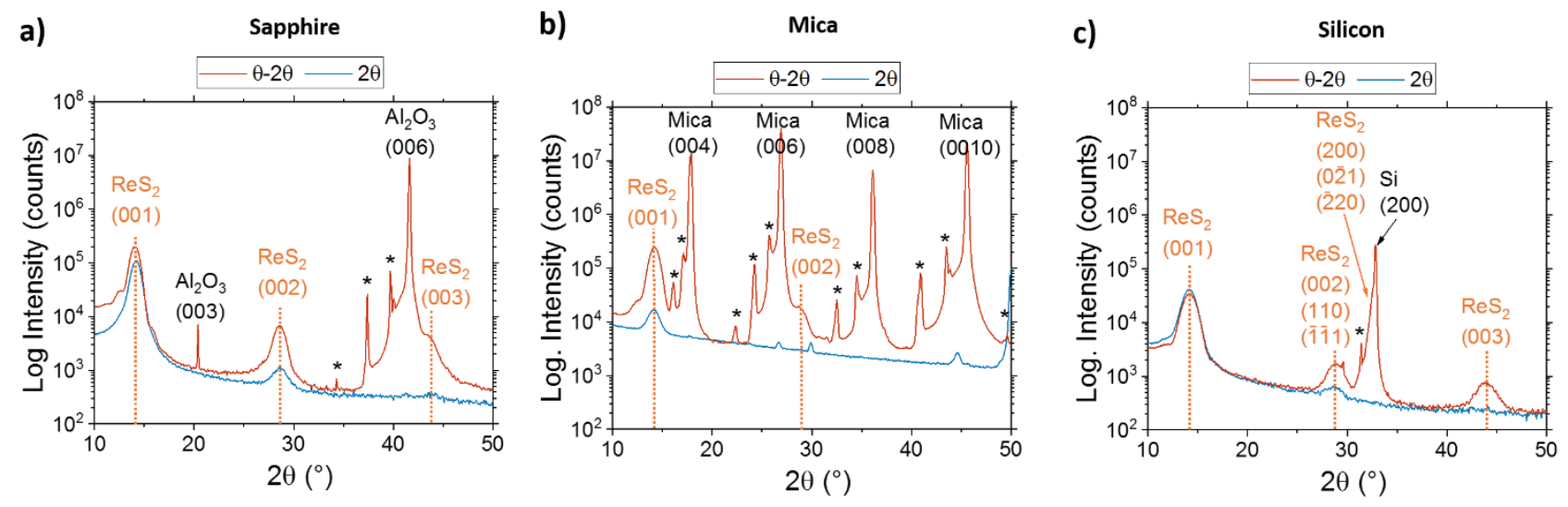

Figure S18. $\theta-2 \theta$ (red) and grazing incidence $\left(2 \theta\right.$, blue) X-ray diffractograms of $\operatorname{ReS}_{2}$ films deposited on a) sapphire, b) mica, and c) silicon using 300 ALD cycles at $400{ }^{\circ} \mathrm{C}$. The $\mathrm{ReS}_{2}$ and substrate reflections are marked in orange and black. Asterisks mark peaks originating from $\mathrm{W} L \alpha$ and $\mathrm{Cu} K \beta$ radiation.

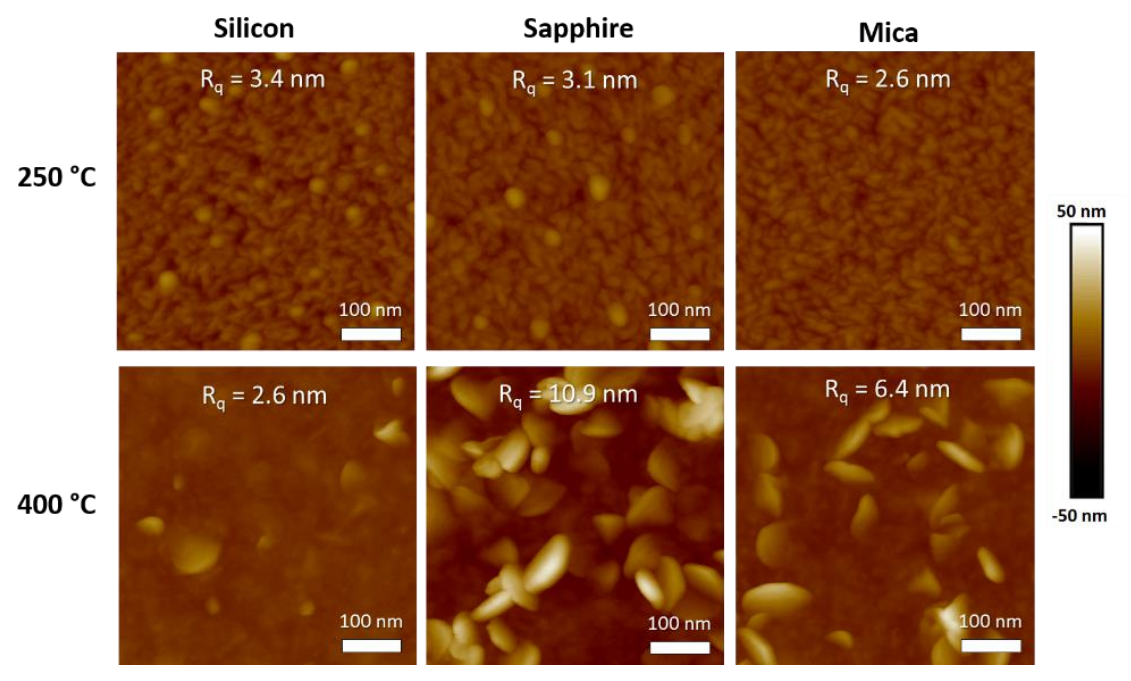

Figure S19. AFM images and roughnesses $\left(\mathrm{R}_{\mathrm{q}}\right)$ of $\mathrm{ReS}_{2}$ films deposited on silicon, sapphire, and mica at $250{ }^{\circ} \mathrm{C}$ (150 ALD cycles) or $400{ }^{\circ} \mathrm{C}$ (300 ALD cycles). 
Section $\mathrm{S} 10 . \mathrm{ZrS}_{2}$ films on sapphire and silicon
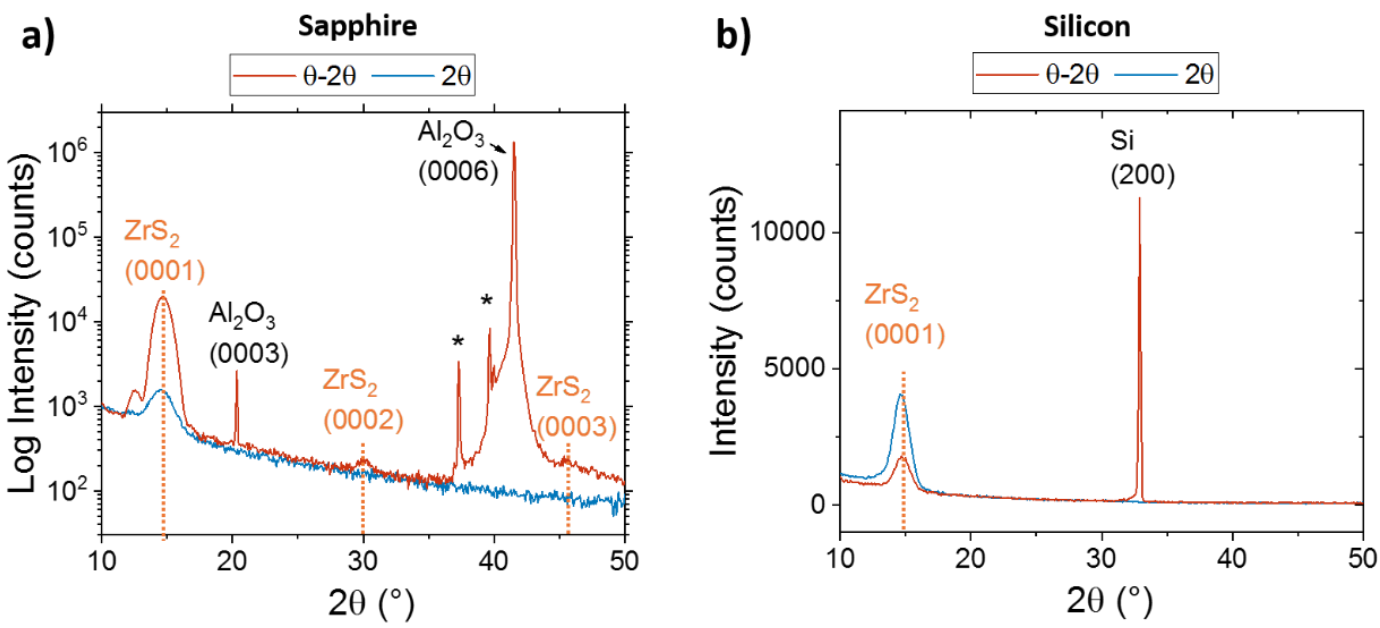

Figure S20. $\theta-2 \theta$ (red) and grazing incidence (2 2 , blue) $\mathrm{X}$-ray diffractograms of $\mathrm{ZrS}_{2}$ films deposited on a) sapphire and b) silicon $\left(\mathrm{SiO}_{2} / \mathrm{Si}\right)$ using $1000 \mathrm{ALD}$ cycles at $400{ }^{\circ} \mathrm{C}$. The $\mathrm{ZrS}_{2}$ and substrate reflections are marked in orange and black. Asterisks mark substrate peaks originating from $\mathrm{W} L \alpha$ and $\mathrm{Cu} \mathrm{K} \beta$ radiation. The much stronger intensity of the $(0001) \mathrm{ZrS}_{2}$ peak on sapphire, especially in the $\theta-2 \theta$ geometry, suggests stronger (0001) texture on sapphire compared to silicon.

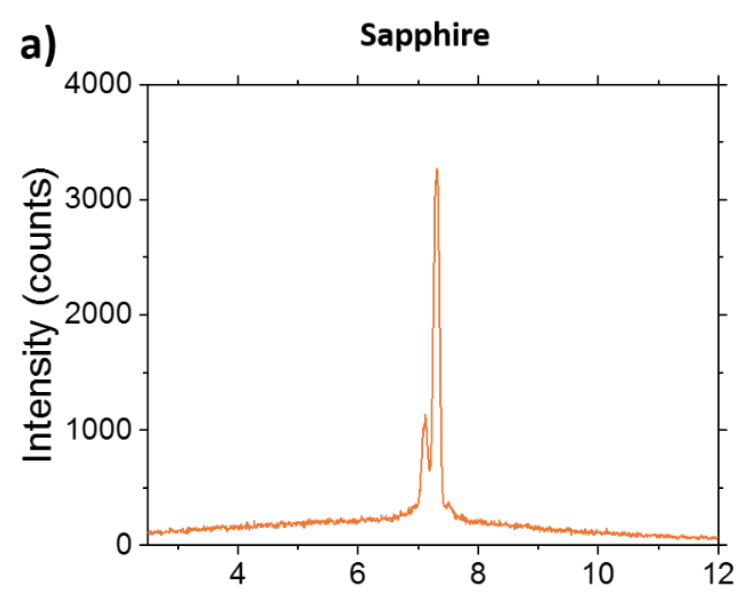

$\omega\left({ }^{\circ}\right)$

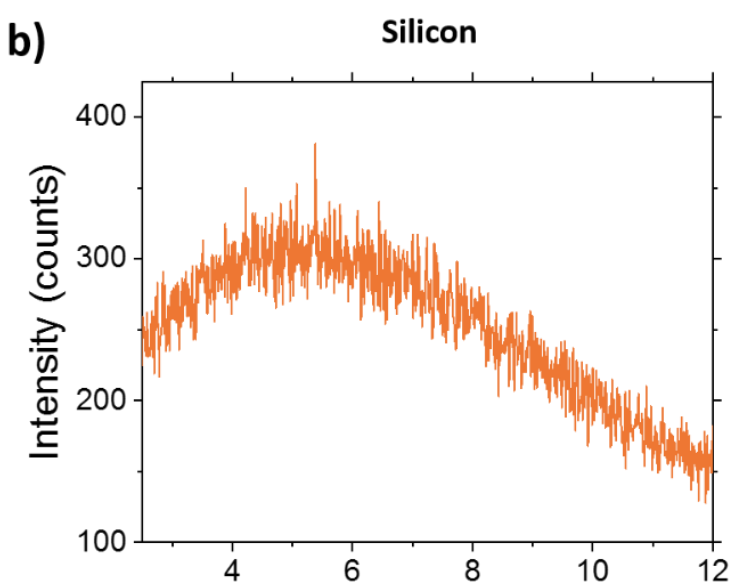

$\omega\left({ }^{\circ}\right)$

Figure S21. Rocking curves of the (0001) reflection (14.6 $\left.{ }^{\circ} 2 \theta\right)$ of $\mathrm{ZrS}_{2}$ films deposited on a) sapphire and b) silicon using 1000 cycles at $400{ }^{\circ} \mathrm{C}$. The sharp peaks on sapphire result from the forbidden (0002)sapphire reflection at $13.6^{\circ} 2 \theta$. Thus, it is difficult to interpret the texture of the films on sapphire using the rocking curve measurements. 

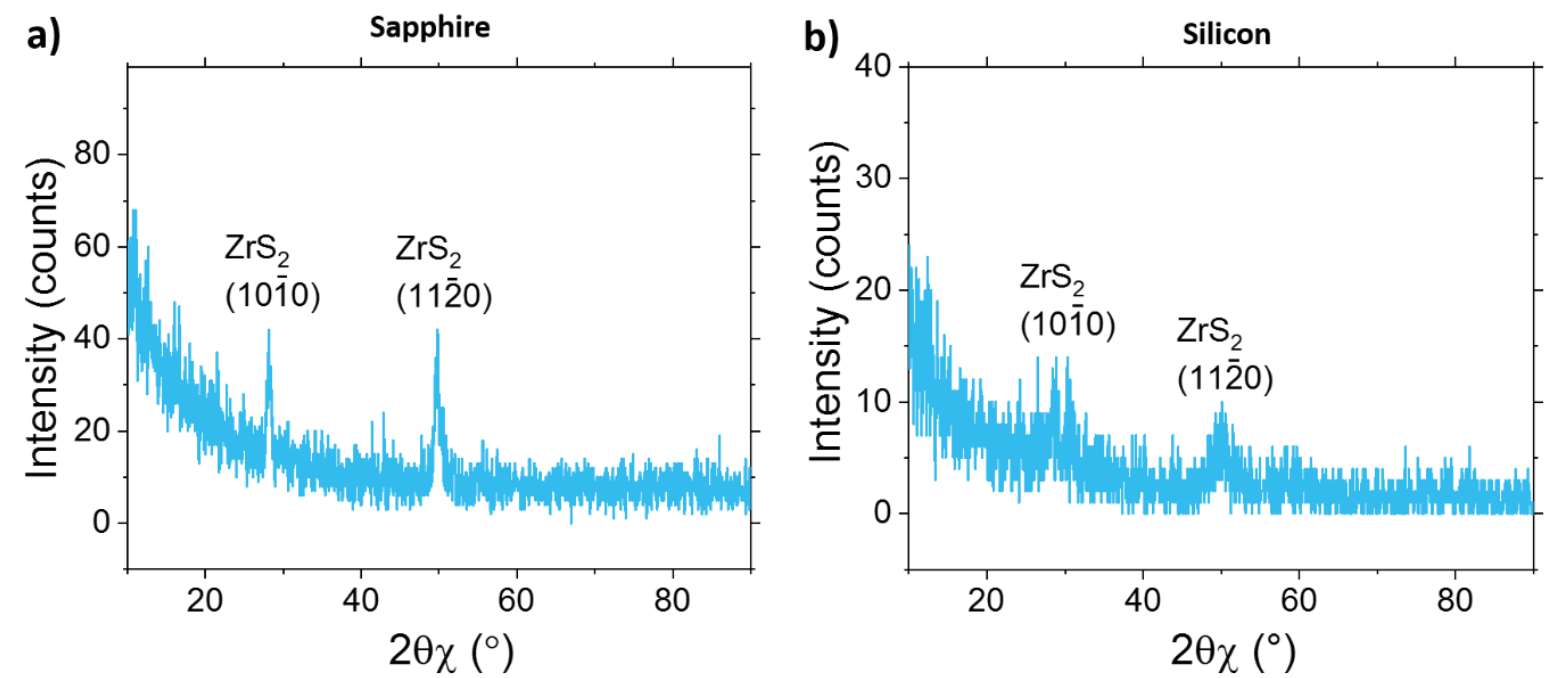

Figure S22. In-plane $2 \theta \chi$ scans of $\mathrm{ZrS}_{2}$ films deposited on a) sapphire and b) silicon using 1000 ALD cycles at $400{ }^{\circ} \mathrm{C}$. The smaller FWHMs of the peaks on sapphire suggest improved crystallinity (inplane crystallite size) compared to the film on silicon.

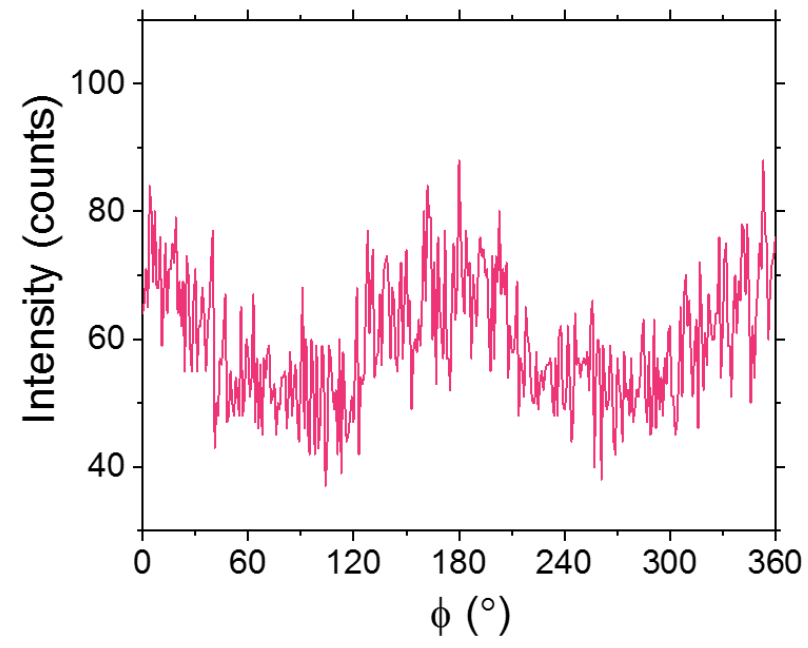

Figure S23. In-plane $\phi$ scan of the $(10 \overline{1} 0) \mathrm{ZrS}_{2}$ reflection $\left(28.2^{\circ} 2 \theta \chi\right)$ of a $\mathrm{ZrS}_{2}$ film deposited on sapphire using 1000 ALD cycles at $400{ }^{\circ} \mathrm{C}$. The absence of clear peaks suggests a lack of epitaxial growth (the variation in the background results from the shape of the sample). 
Section S11. Characterization of $\mathrm{PbI}_{2}$ films on mica

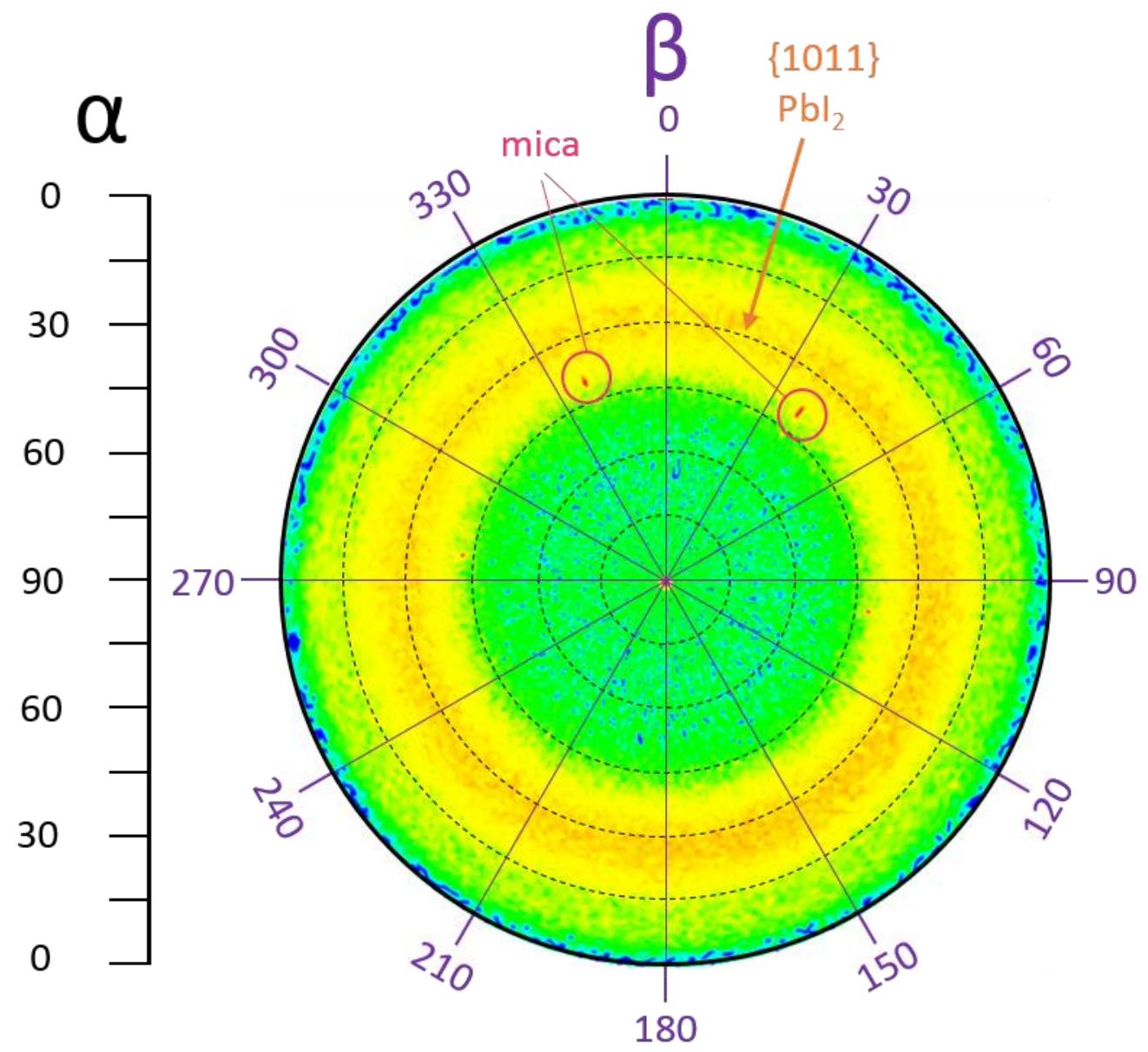

\section{High}

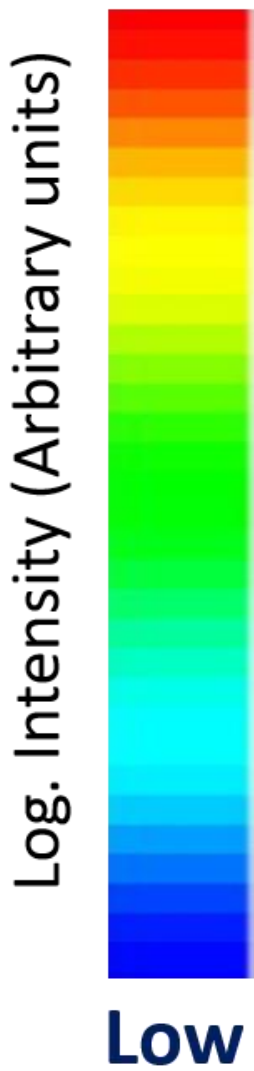

Figure S24. In-plane pole figure of a $\mathrm{PbI}_{2}$ film on mica at $25.85^{\circ}{ }^{\circ} 2 \theta$ showing a ring resulting from the $\{10 \overline{1} 1\} \mathrm{PbI}_{2}$ reflection. The presence of a diffuse ring centered at approximately $30{ }^{\circ} \alpha$ indicates non-epitaxial orientation of the $\mathrm{PbI}_{2}$ crystallites (compared with Figure $3 \mathrm{~b}$ showing epitaxial $\mathrm{PbI}_{2}$ on sapphire). The sharp peaks originate from the mica substrate. 

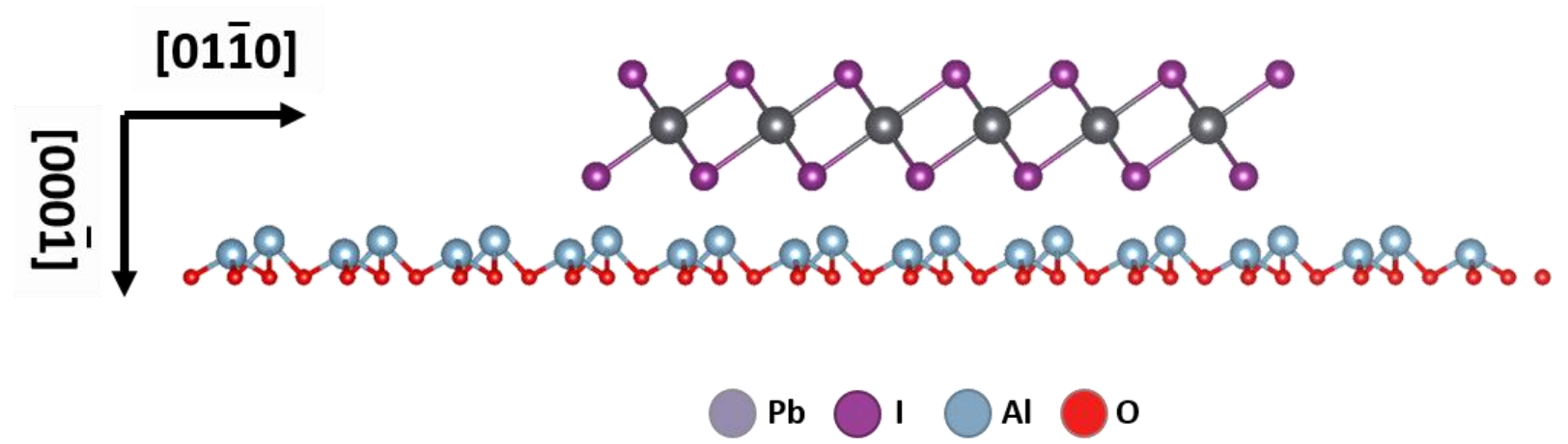

Figure S25. Cross-sectional view of an epitaxially aligned $\mathrm{PbI}_{2}$ domain on a sapphire surface according to the relation $(001)[2 \overline{11} 0] \mathrm{PbI}_{2} \|(001)[2 \overline{11} 0] \mathrm{Al}_{2} \mathrm{O}_{3}$. For clarity, only one $\mathrm{PbI}_{2}$ layer and the top layer of $\mathrm{Al}_{2} \mathrm{O}_{3}$ are drawn.

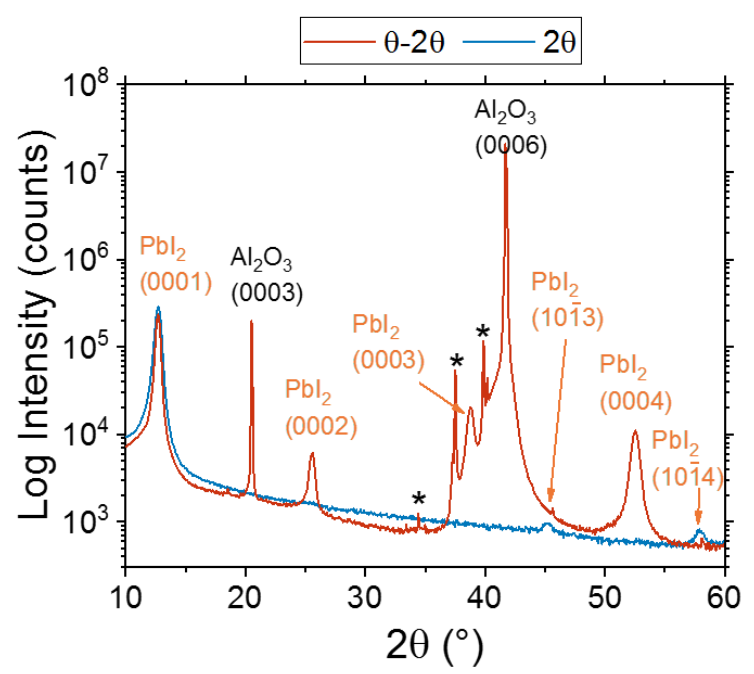

Figure S26. $\theta-2 \theta$ (red) and grazing incidence $\left(2 \theta\right.$, blue) X-ray diffractograms of a $\mathrm{PbI}_{2}$ film deposited on sapphire using $2000 \mathrm{ALD}$ cycles at $75^{\circ} \mathrm{C}$. The $\mathrm{PbI}_{2}$ and substrate reflections are marked in orange and black. Asterisks mark substrate peaks originating from $\mathrm{W} L \alpha$ and $\mathrm{Cu} K \beta$ radiation. The approximately identical intensity of the (0001) $\mathrm{PbI}_{2}$ reflection in the $2 \theta$ and $\theta-2 \theta$ geometries as well as the presence of weak $(10 \overline{1} 3)$ and $(10 \overline{1} 4)$ reflections suggest a presence of some domains with imperfect out-of-plane orientation. 


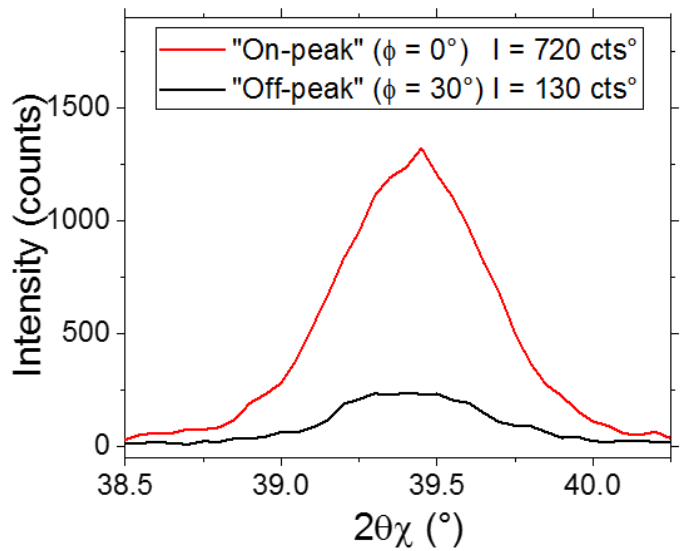

Figure S27. In-plane $2 \theta \chi$ scans of a $\mathrm{PbI}_{2}$ film deposited on sapphire using 2000 ALD cycles at 75 ${ }^{\circ} \mathrm{C}$. The scans were performed around the $(11 \overline{2} 0) \mathrm{PbI}_{2}$ reflection at two different $\phi$ angles, $0^{\circ}$ corresponding to epitaxial grains (red) and $30^{\circ}$ to non-epitaxial grains (black).
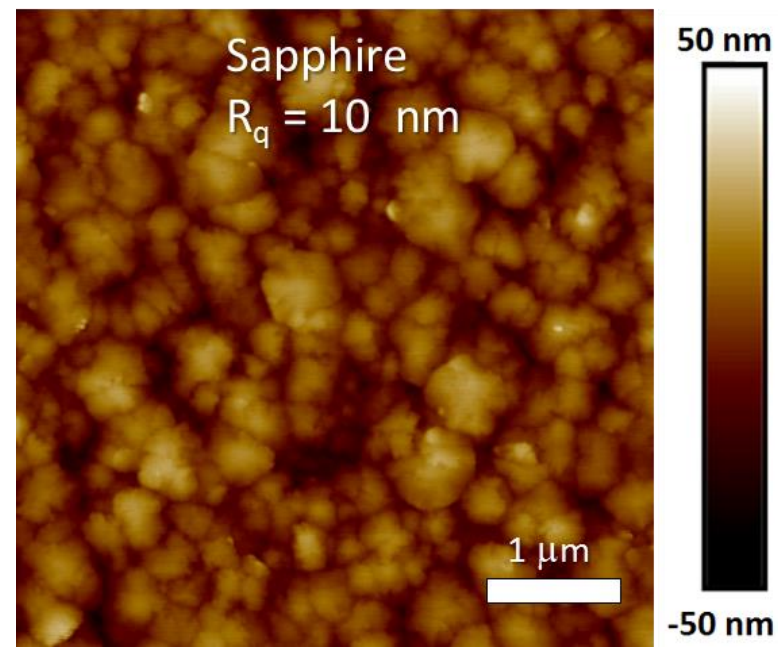

Figure S28. AFM image and roughness $\left(\mathrm{R}_{\mathrm{q}}\right)$ of a $\mathrm{PbI}_{2}$ film deposited on sapphire at $75^{\circ} \mathrm{C}$ using 2000 ALD cycles. Some flakes pointing away from the surface suggest presence of non-epitaxial domains. The reason for the relatively large roughness resulting from the tens of $\mathrm{nm}$ high pyramidal (conical) grains is not currently understood. 


\section{Section S13. vdW epitaxy in literature}

In this section, selected examples of vdW epitaxy reported in literature are discussed and compared to the present work. The discussion and the results tabulated in Table S2 are not meant to be exhaustive - for example the vdW epitaxy of organic materials is omitted. The majority of the vdW epitaxy papers report growth of a 2D film on either a 2D substrate (e.g. graphite, $\mathrm{MoS}_{2}$ ) or a 3D substrate with an inert surface (e.g. $\mathrm{AlN}, \mathrm{Al}_{2} \mathrm{O}_{3}, \mathrm{GaAs}$ ) perhaps following a chalcogenization treatment. Many examples have been reported on the growth of 2D TMDCs on another hexagonal 2D material, including TMDCs, h-BN, and graphite/graphene. In these cases, typically the $<10 \overline{1} 0>$ directions (i.e. $[10 \overline{1} 0],[0 \overline{1} 10],[\overline{1} 100])$ or $60^{\circ}$ rotated $<\overline{1} 010>$ ((i.e. [1010], [01 $\left.\left.\overline{1} 0\right],[1 \overline{1} 00]\right)$ ) directions of the film and the substrate are reported to be aligned. Equivalently, the parallel alignment can be defined using the $\langle 2 \overline{110}\rangle$ (i.e. [2 $\overline{11} 0],[\overline{1} 2 \overline{1} 0],[\overline{11} 20]$ ) and the $\langle\overline{2} 110\rangle$ (i.e. $[\overline{2} 110],[1 \overline{2} 10],[11 \overline{2} 0])$ directions, which are at an angle of $30^{\circ}$ and $90^{\circ}$ with respect to $<10 \overline{1} 0>$ in the crystal structure of TMDCs. We chose to use the latter directions to specify the epitaxial relationships. Another commonly reported alignment is between the $<10 \overline{1} 0>$ direction of the film and the $<2 \overline{110}>$ direction of the substrate (or vice versa), which corresponds to a $30^{\circ}$ rotation between the film and the substrate.

Similar 0 or $30^{\circ}$ rotation is also usually observed for $2 \mathrm{D}$ materials grown on the trigonal sapphire and on different micas, which can be considered to have a somewhat distorted hexagonal surface structure (in this case, [100]mica equates to $\langle 2 \overline{110}>$ in the hexagonal notation, which is related to $<$ $11 \overline{2} 0>$ by a $60^{\circ}$ rotation). It should be noted that due to the six-fold symmetry of the $\{10 \overline{1} 0\}$ or $\{11 \overline{2} 0\}$ planes used to define the alignment compared to the three-fold rotational symmetry of (at least monolayer) TMDCs, it is not trivial to distinguish between the 0 and $60^{\circ}$ orientations, which are mirror twins of each other (as are the 30 and $90^{\circ}$ orientations), and will result in mirror grain boundaries between them. Some reports also demonstrate interesting examples of the vdW epitaxy of different 3D materials, including fcc and hcp metals, Ge, and ZnTe grown on 2D substrates. In these cases the epitaxial relationships vary likely due to the different crystal structures.

In terms of deposition techniques and conditions, vdW epitaxy is usually realized using either MBE or some other PVD technique in UHV conditions and possibly high temperatures, or CVD at high temperatures, typically $700-1000{ }^{\circ} \mathrm{C}$. High temperatures limit compatibility with different substrates, whereas UHV processing is expensive. Furthermore, MBE or CVD cannot offer the typical advantages of ALD, such as scalability, large-area uniformity, and conformality. 
Table S2. Selected examples of vdW epitaxy reported in literature. The reports have been classified into MBE, other PVD, and CVD. The majority of the grown films have been layered (2D) materials, but a few 3D materials have also been demonstrated as listed.

Film / substrate

\section{Layered (2D) films}

\begin{tabular}{|c|c|c|c|}
\hline $\mathrm{HfTe}_{2} /(\mathbf{0 0 0 1}) \mathrm{AlN}$ & $530{ }^{\circ} \mathrm{C}\left(10^{-10}\right.$ Torr $)$ & $(0001)[10 \overline{1} 0] \mathrm{HfTe}_{2} \|(0001)[10 \overline{1} 0] \mathrm{AlN}$ & 14 \\
\hline $\mathrm{MoSe}_{2} /(\mathbf{1 1 1}) \mathrm{GaAs}$ & $\begin{array}{c}470-530{ }^{\circ} \mathrm{C}\left(10^{-7}\right. \\
\text { mbar })\end{array}$ & $\begin{array}{c}(0002)[10 \overline{1} 0] \mathrm{MoSe}_{2} \|(111)[11 \overline{1} 2] \mathrm{GaAs} \boldsymbol{\&} \\
\quad(0002)[11 \overline{2} 0] \mathrm{MoSe}_{2} \|(111)[10 \overline{1}] \mathrm{GaAs}\end{array}$ & 15 \\
\hline $\mathrm{MoSe}_{2} /\{\mathbf{1 1 1}\} \mathrm{S}-\mathrm{GaAs}$ & $400^{\circ} \mathrm{C}\left(10^{-8} \mathrm{~Pa}\right)$ & $(0001)[11 \overline{2} 0] \mathrm{MoSe}_{2} \|(111)[10 \overline{1}] \mathrm{GaAs}$ & 16 \\
\hline $\mathrm{NbSe}_{2} /(\mathbf{0 0 1})$ mica & $450{ }^{\circ} \mathrm{C}\left(10^{-8} \mathrm{~Pa}\right)$ & $\begin{array}{c}(0001)[11 \overline{2} 0] \mathrm{NbSe}_{2} \|(001)[100] \text { mica, some } \\
\text { polycrystalline domains }\end{array}$ & 17 \\
\hline $\mathrm{PbI}_{2} /(\mathbf{0 0 0 1}) \mathrm{MoS}_{2}$ & $150{ }^{\circ} \mathrm{C}\left(10^{-8} \mathrm{~Pa}\right)$ & $(0001)[10 \overline{1} 0] \mathrm{PbI}_{2} \|(0001)[2 \overline{11} 0] \mathrm{MoS}_{2}$ & 18 \\
\hline $\mathrm{PbI}_{2} /(\mathbf{0 0 0 1}) \mathrm{MoSe}_{2}$ & $150{ }^{\circ} \mathrm{C}\left(10^{-8} \mathrm{~Pa}\right)$ & $\begin{array}{c}(0001)[10 \overline{1} 0] \mathrm{PbI}_{2} \|(0001)[2 \overline{11} 0] \mathrm{MoSe}_{2} \boldsymbol{\alpha} \\
(0001)[10 \overline{1} 0] \mathrm{PbI}_{2} \|(0001)[10 \overline{1} 0] \mathrm{MoSe}_{2}\end{array}$ & 18 \\
\hline $\mathrm{PbI}_{2} /(\mathbf{0 0 0 1}) \mathrm{NbSe}_{2}$ & $150^{\circ} \mathrm{C}\left(10^{-8} \mathrm{~Pa}\right)$ & $\begin{array}{c}(0001) \mathrm{PbI}_{2} \|(0001) \mathrm{NbSe}_{2}, 19^{\circ} \text { offset } \\
\text { between }[2 \overline{11} 0] \text { of } \mathrm{PbI}_{2} \text { and } \mathrm{NbSe}_{2}\end{array}$ & 18 \\
\hline $\mathrm{PbI}_{2} /(\overline{\mathbf{1 1 1}}) \mathrm{Se}-\mathrm{GaAs}$ & $150{ }^{\circ} \mathrm{C}\left(10^{-8} \mathrm{~Pa}\right)$ & $(0001)[2 \overline{11} 0] \mathrm{PbI}_{2} \|(0001)[2 \overline{11} 0] \mathrm{GaSe}$ & 18 \\
\hline $\mathrm{SnS}_{2} /(\mathbf{0 0 1}) \mathrm{mica}$ & $325^{\circ} \mathrm{C}\left(10^{-8}\right.$ Torr $)$ & $\begin{array}{c}(0001)[11 \overline{2} 0] \mathrm{SnS}_{2} \|(001)[100] \text { mica } \boldsymbol{\&} 30^{\circ} \\
\text { rotated domains }\end{array}$ & 19 \\
\hline $\mathrm{VTe}_{2} /(\mathbf{0 0 1})$ mica & $350^{\circ} \mathrm{C}\left(10^{-8} \mathrm{mbar}\right)$ & $(001)[100] \mathrm{VTe}_{2} \|(001)[100] \mathrm{mica}$ & 20 \\
\hline $\mathrm{WSe}_{2} /$ (0001)sapphire & $\begin{array}{c}450+900^{\circ} \mathrm{C} \text { anneal } \\
\left(10^{-7} \mathrm{~Pa}\right)\end{array}$ & $(001)[100] \mathrm{WSe}_{2} \|(001)[100]$ sapphire & 21 \\
\hline
\end{tabular}

\section{Other physical vapor deposition (PVD) methods}

\section{Layered (2D) films}
$\mathrm{MoS}_{2} /(\mathbf{1 1 1}) \mathrm{Au}$
$550{ }^{\circ} \mathrm{C}\left(10^{-6} \mathrm{mbar}\right)$

$\mathrm{PbI}_{2} /(\mathbf{0 0 1})$ mica

$150{ }^{\circ} \mathrm{C}\left(10^{-8} \mathrm{~Pa}\right)$

$\mathrm{SnS} /$ (0001) graphene $\quad 285^{\circ} \mathrm{C}\left(10^{-7}\right.$ Torr $)$

$\mathrm{WSe}_{2} / \mathrm{SnS}_{2}$

$$
600{ }^{\circ} \mathrm{C}(8 \text { Torr })
$$

(0001) $\mathrm{MoS}_{2}$ || (111)Au, single in-plane orientation

Ref.

\section{Molecular beam epitaxy (MBE)}




\begin{tabular}{|c|c|c|c|}
\hline $\mathrm{Ge} /(\mathbf{0 0 1}) \mathrm{mica}$ & $\begin{array}{l}300-500{ }^{\circ} \mathrm{C} \\
\left(10^{-7} \text { Torr }\right)\end{array}$ & $\begin{array}{c}(111) \mathrm{Ge} \|(001) \mathrm{mica}, 20^{\circ} \times \mathrm{n}(\mathrm{n}=0,1, \ldots, 5) \\
\text { offset between }[\overline{1} 10] \mathrm{Ge} \text { and }[100] \mathrm{mica}\end{array}$ & 27 \\
\hline $\begin{array}{c}\mathrm{M} /(\mathbf{0 0 0 1}) \mathrm{MoS}_{2} \\
\mathrm{M}=\mathrm{Ag}, \mathrm{Au}, \mathrm{Al}, \mathrm{Cu}, \mathrm{Pd}, \\
\mathrm{Pt}\end{array}$ & $\mathrm{RT}\left(10^{-8}\right.$ Torr $)$ & $(111)[2 \overline{2} 0] \mathrm{M} \|(001)[11 \overline{2} 0] \mathrm{MoS}_{2}$ & 28 \\
\hline $\mathrm{ZnTe} /$ (0001)graphene & $300{ }^{\circ} \mathrm{C}\left(10^{-7}\right.$ Torr $)$ & $\begin{array}{l}(111)[\overline{11} 2] \mathrm{ZnTe} \|(001)[10] \text { graphene } \boldsymbol{\&} \\
\quad(111)[\overline{11} 2] \mathrm{ZnTe} \|(001)[11] \text { graphene }\end{array}$ & 29 \\
\hline
\end{tabular}

\section{Layered (2D) films}

$\begin{array}{llll}\mathrm{HfS}_{2} /(\text { (0001)sapphire } & 1000{ }^{\circ} \mathrm{C}(20 \mathrm{~Pa}) & (0001)[10 \overline{1} 0] \mathrm{HfS}_{2} \|(0001)[1 \overline{1} 00] \text { sapphire } & 30 \\ \mathrm{MeS}_{2} / \text { fluop } & & \end{array}$

$\mathrm{MoS}_{2} /$ fluorophlogopite $530{ }^{\circ} \mathrm{C}(30 \mathrm{~Pa}) \quad$ (0001) $\mathrm{MoS}_{2} \|(001)$ mica, in-plane 0 and $60^{\circ} \quad 31$

mica

$\begin{array}{ll}\mathrm{MoSe}_{2} /(\mathbf{0 0 0 1}) \mathrm{GaN} & 860{ }^{\circ} \mathrm{C}(1 \mathrm{~atm}) \\ \mathrm{MoS}_{2} /(\mathbf{0 0 0 1}) \text { graphene } & 800^{\circ} \mathrm{C}(43 \mathrm{Torr})\end{array}$ domains
$\mathrm{MoS}_{2} /(\mathbf{0 0 0 1})$ sapphire $\quad 800{ }^{\circ} \mathrm{C}(40$ Torr $) \quad$ (0001) $\mathrm{MoS}_{2} \|$ (0001)sapphire, in-plane 0 and ${ }^{34}$ $60^{\circ}$ domains
$\mathrm{MoS}_{2} /(\mathbf{0 0 0 1})$ sapphire $\quad 700{ }^{\circ} \mathrm{C}(1 \mathrm{~atm}) \quad$ (0001) $\mathrm{MoS}_{2} \|(0001)$ sapphire, in-plane $91 \% 0 \quad 35$ or $60^{\circ}, 6 \% 30$ or $90^{\circ}, 2.5 \%$ other domains
$\mathrm{MoS}_{2} /$ (0001)sapphire $930{ }^{\circ} \mathrm{C}(1$ Torr $) \quad$ (0001) $\mathrm{MoS}_{2} \|$ (0001)sapphire, in-plane $0^{\circ} \quad 36$ (and 60) domains
$\mathrm{MoS}_{2} /$ (0001)sapphire $930{ }^{\circ} \mathrm{C}(1 \mathrm{~atm})$ (0001) $\mathrm{MoS}_{2}$ || (0001)sapphire, in-plane either 37 $0 / 60^{\circ}$ or $30 / 90^{\circ}$ domains depending on S supply
$\mathrm{MoS}_{2} /(\mathbf{0 0 0 1})$ sapphire $900{ }^{\circ} \mathrm{C}$ (0001)[10 $\overline{1} 0] \mathrm{MoS}_{2} \|(0001)[10 \overline{1} 0]$ sapphire ${ }^{38}$ and $60^{\circ}$ domains
$\begin{array}{llll}\mathrm{MoS}_{2} /(\mathbf{0 0 0 1}) \mathrm{SnS}_{2} & 420-470{ }^{\circ} \mathrm{C}(1 \mathrm{~atm}) & (0001) \mathrm{MoS}_{2} \|(0001) \mathrm{SnS}_{2}, 1^{\circ} \text { offset in-plane } & { }^{39} \\ \mathrm{WSe}_{2} /(\mathbf{0 0 0 1}) \mathrm{h}-\mathrm{BN} & 800{ }^{\circ} \mathrm{C}(700 \text { Torr }) & (0001)[1 \overline{1} 00] \mathrm{WSe}_{2} \| \quad(0001)[1 \overline{1} 00] \mathrm{h}-\mathrm{BN} & { }^{40}\end{array}$ (very few $60^{\circ}$ domains)
$\mathrm{WSe}_{2} /(\mathbf{0 0 0 1})$ sapphire $\quad 800{ }^{\circ} \mathrm{C}(700$ Torr $) \quad$ (0001)[1010]WSe $\|(0001)[10 \overline{1} 0]$ sapphire ${ }^{41}$ and $60^{\circ}$ domains

\section{Non-layered (3D) films}

AlN / (0001)graphene $1100{ }^{\circ} \mathrm{C}(?)$ 


\section{Section S14. References}

(1) Mattinen, M.; Popov, G.; Vehkamäki, M.; King, P. J.; Mizohata, K.; Jalkanen, P.; Räisänen, J.; Leskelä, M.; Ritala, M. Atomic Layer Deposition of Emerging 2D Semiconductors, $\mathrm{HfS}_{2}$ and $\mathrm{ZrS}_{2}$, for Optoelectronics. Chem. Mater. 2019, 31, 5713-5724.

(2) Mattinen, M.; Hatanpää, T.; Sarnet, T.; Mizohata, K.; Meinander, K.; King, P. J.; Khriachtchev, L.; Räisänen, J.; Ritala, M.; Leskelä, M. Atomic Layer Deposition of Crystalline $\mathrm{MoS}_{2}$ Thin Films: New Molybdenum Precursor for Low-Temperature Film Growth. Adv. Mater. Interfaces 2017, 4, 1700213.

(3) Popov, G.; Mattinen, M.; Hatanpää, T.; Vehkamäki, M.; Kemell, M.; Mizohata, K.; Räisänen, J.; Ritala, M.; Leskelä, M. Atomic Layer Deposition of $\mathrm{PbI}_{2}$ Thin Films. Chem. Mater. 2019, 31, 1101-1109.

(4) Mattinen, M.; King, P. J.; Khriachtchev, L.; Meinander, K.; Gibbon, J. T.; Dhanak, V. R.; Räisänen, J.; Ritala, M.; Leskelä, M. Low-Temperature Wafer-Scale Deposition of Continuous 2D SnS 2 Films. Small 2018, 14, 1800547.

(5) Hämäläinen, J.; Mattinen, M.; Mizohata, K.; Meinander, K.; Vehkamäki, M.; Räisänen, J.; Ritala, M.; Leskelä, M. Atomic Layer Deposition of Rhenium Disulfide. Adv. Mater. 2018, 30, 1703622.

(6) Ribic, P. R.; Bratina, G. Behavior of the (0001) Surface of Sapphire upon High-Temperature Annealing. Surf. Sci. 2007, 601, 44-49.

(7) Yoshimoto, M.; Maeda, T.; Ohnishi, T.; Koinuma, H.; Ishiyama, O.; Shinohara, M.; Kubo, M.; Miura, R.; Miyamoto, A. Atomic-Scale Formation of Ultrasmooth Surfaces on Sapphire Substrates for High-Quality Thin-Film Fabrication. Appl. Phys. Lett. 1995, 67, 2615-2617.

(8) De Poel, W.; Pintea, S.; Drnec, J.; Carla, F.; Felici, R.; Mulder, P.; Elemans, J. A. A. W.; Van Enckevort, W. J. P.; Rowan, A. E.; Vlieg, E. Muscovite Mica: Flatter than a Pancake. Surf. Sci. 2014, 619, 19-24.

(9) Waldo, R. A. An Iteration Procedure to Calculate Film Compositions and Thicknesses in Electron-Probe Microanalysis. In Microbeam Analysis; Newbury, D. E., Ed.; San Francisco Press: San Francisco, 1988; pp 310-314.

(10) CRC Handbook of Chemistry and Physics, 98th ed.; available online at http://www.hbcpnetbase.com, accessed 25.3.2018.

(11) Kobayashi, S. X-Ray Thin Film Measurements Techniques IV. In-Plane XRD Measurements. Rigaku J. 2010, 26, 3-11.

(12) Nagao, K.; Kagami, E. X-Ray Thin Film Measurement Techniques VII. Pole Figure Measurements. Rigaku J. 2011, 27, 6-14.

(13) Momma, K.; Izumi, F. VESTA3 for Three-Dimensional Visualization of Crystal, Volumetric and Morphology Data. J. Appl. Crystallogr. 2011, 44, 1272-1276.

(14) Aminalragia-Giamini, S.; Marquez-Velasco, J.; Tsipas, P.; Tsoutsou, D.; Renaud, G.; Dimoulas, A. Molecular Beam Epitaxy of Thin HfTe 2 Semimetal Films. 2D Mater. 2017, 4, 015001.

(15) Chen, M.-W.; Ovchinnikov, D.; Lazar, S.; Pizzochero, M.; Whitwick, M. B.; Surrente, A.; Baranowski, M.; Sanchez, O. L.; Gillet, P.; Plochocka, P.; Yazyev, O. V.; Kis, A. Highly Oriented Atomically Thin Ambipolar $\mathrm{MoSe}_{2}$ Grown by Molecular Beam Epitaxy. ACS Nano 2017, 11, 6355-6361.

(16) Ueno, K.; Shimada, T.; Saiki, K.; Koma, A. Heteroepitaxial Growth of Layered Transition Metal Dichalcogenides on Sulfur-Terminated GaAs $\{111\}$ Surfaces. Appl. Phys. Lett. 1990, 56, 327-329.

(17) Saiki, K.; Ueno, K.; Shimada, T.; Koma, A. Application of van Der Waals Epitaxy to Highly Heterogeneous Systems. J. Cryst. Growth 1989, 95, 603-606.

(18) Ueno, T.; Yamamoto, H.; Saiki, K.; Koma, A. Van Der Waals Epitaxy of Metal Dihalide. Appl. 
Surf. Sci. 1997, 113-114, 33-37.

(19) Nebesny, K. W.; Collins, G. E.; Lee, P. A.; Chau, L.-K.; Danziger, J.; Osburn, E.; Armstrong, N. R. Organic/Inorganic Molecular Beam Epitaxy: Formation of an Ordered Phthalocyanine/SnS 2 Heterojunction. Chem. Mater. 1991, 3, 829-838.

(20) Ma, X.; Dai, T.; Dang, S.; Kang, S.; Chen, X.; Zhou, W.; Wang, G.; Li, H.; Hu, P.; He, Z.; Sun, Y.; Li, D.; Yu, F.; Zhou, X.; Chen, H.; Chen, X.; Wu, S.; Li, S. Charge Density Wave Phase Transitions in Large-Scale Few-Layer 1T-VTe 2 Grown by Molecular Beam Epitaxy. ACS Appl. Mater. Interfaces 2019, 11, 10729-10735.

(21) Nakano, M.; Wang, Y.; Kashiwabara, Y.; Matsuoka, H.; Iwasa, Y. Layer-by-Layer Epitaxial Growth of Scalable WSe 2 on Sapphire by Molecular Beam Epitaxy. Nano Lett. 2017, 17, 5595-5599.

(22) Bana, H.; Travaglia, E.; Bignardi, L.; Lacovig, P.; Sanders, C. E.; Dendzik, M.; Michiardi, M.; Bianchi, M.; Lizzit, D.; Presel, F.; De Angelis, D.; Apostol, N.; Das, P. K.; Fujii, J.; Vobornik, I.; Larciprete, R.; Baraldi, A.; Hofmann, P.; Lizzit, S. Epitaxial Growth of Single-Orientation High-Quality $\mathrm{MoS}_{2}$ Monolayers. 2D Mater. 2018, 5, 035012.

(23) Wang, Y.; Sun, Y.-Y.; Zhang, S.; Lu, T.-M.; Shi, J. Band Gap Engineering of a Soft Inorganic Compound $\mathrm{PbI}_{2}$ by Incommensurate van Der Waals Epitaxy. Appl. Phys. Lett. 2016, 108, 013105.

(24) Xiang, Y.; Yang, Y.; Guo, F.; Sun, X.; Lu, Z.; Mohanty, D.; Bhat, I.; Washington, M.; Lu, T.M.; Wang, G.-C. Van Der Waals Epitaxy of SnS Film on Single Crystal Graphene Buffer Layer on Amorphous $\mathrm{SiO}_{2} / \mathrm{Si}$. Appl. Surf. Sci. 2018, 435, 759-768.

(25) Yang, T.; Zheng, B.; Wang, Z.; Xu, T.; Pan, C.; Zou, J.; Zhang, X.; Qi, Z.; Liu, H.; Feng, Y.; Hu, W.; Miao, F.; Sun, L.; Duan, X.; Pan, A. Van Der Waals Epitaxial Growth and Optoelectronics of Large-Scale $\mathrm{WSe}_{2} / \mathrm{SnS}_{2}$ Vertical Bilayer $\mathrm{p}-\mathrm{n}$ Junctions. Nat. Commun. 2017, 8, 1906.

(26) Ke, S.; Xie, J.; Chen, C.; Lin, P.; Zeng, X.; Shu, L.; Fei, L.; Wang, Y.; Ye, M.; Wang, D. Van Der Waals Epitaxy of Al-Doped ZnO Film on Mica as a Flexible Transparent Heater with Ultrafast Thermal Response. Appl. Phys. Lett. 2018, 112, 031905.

(27) Littlejohn, A. J.; Xiang, Y.; Rauch, E.; Lu, T.-M.; Wang, G.-C. Van Der Waals Epitaxy of Ge Films on Mica. J. Appl. Phys. 2017, 122, 185305.

(28) Domask, A. C.; Cooley, K. A.; Kabius, B.; Abraham, M.; Mohney, S. E. Room Temperature van Der Waals Epitaxy of Metal Thin Films on Molybdenum Disulfide. Cryst. Growth Des. 2018, 18, 3494-3501.

(29) Sun, X.; Chen, Z.; Wang, Y.; Lu, Z.; Shi, J.; Washington, M.; Lu, T.-M. Van Der Waals Epitaxial ZnTe Thin Film on Single-Crystalline Graphene. J. Appl. Phys. 2018, 123, 025303.

(30) Wang, D.; Zhang, X.; Liu, H.; Meng, J.; Xia, J.; Yin, Z.; Wang, Y.; You, J.; Meng, X.-M. Epitaxial Growth of $\mathrm{HfS}_{2}$ on Sapphire by Chemical Vapor Deposition and Application for Photodetectors. 2D Mater. 2017, 4, 031012.

(31) Ji, Q.; Zhang, Y.; Gao, T.; Zhang, Y.; Ma, D.; Liu, M.; Chen, Y.; Qiao, X.; Tan, P.-H.; Kan, M.; Feng, J.; Sun, Q.; Liu, Z. Epitaxial Monolayer $\mathrm{MoS}_{2}$ with Novel Photoluminescence. Nano Lett. 2013, 13, 3870-3877.

(32) Chen, Z.; Liu, H.; Chen, X.; Chu, G.; Chu, S.; Zhang, H. Wafer-Size and Single-Crystal MoSe 2 Atomically Thin Films Grown on GaN Substrate for Light Emission and Harvesting. ACS Appl. Mater. Interfaces 2016, 8, 20267-20273.

(33) Liu, X.; Balla, I.; Bergeron, H.; Campbell, G. P.; Bedzyk, M. J.; Hersam, M. C. Rotationally Commensurate Growth of $\mathrm{MoS}_{2}$ on Epitaxial Graphene. ACS Nano 2016, 10, 1067-1075.

(34) Aljarb, A.; Cao, Z.; Tang, H.-L.; Huang, J.-K.; Li, M.; Hu, W.; Cavallo, L.; Li, L.-J. Substrate Lattice-Guided Seed Formation Controls the Orientation of 2D Transition Metal Dichalcogenides. ACS Nano 2017, 11, 9215-9222.

(35) Dumcenco, D.; Ovchinnikov, D.; Marinov, K.; Lazic, P.; Gibertini, M.; Marzari, N.; Sanchez, 
O. L.; Kung, Y.; Krasnozhon, D.; Chen, M.-W.; Bertolazzi, S.; Gillet, P.; Fontcuberta I Morral, A.; Radenovic, A.; Kis, A. Large-Area Epitaxial Monolayer $\mathrm{MoS}_{2}$. ACS Nano 2015, 9, 46114620.

(36) Yu, H.; Liao, M.; Zhao, W.; Liu, G.; Zhou, X. J.; Wei, Z.; Xu, X.; Liu, K.; Hu, Z.; Deng, K.; Zhou, S.; Shi, J.-A.; Gu, L.; Shen, C.; Zhang, T.; Du, L.; Xie, L.; Zhu, J.; Chen, W.; Yang, R.; Shi, D.; Zhang, G. Wafer-Scale Growth and Transfer of Highly-Oriented Monolayer $\mathrm{MoS}_{2}$ Continuous Films. ACS Nano 2017, 11, 12001-12007.

(37) Suenaga, K.; Ji, H. G.; Lin, Y.-C.; Vincent, T.; Maruyama, M.; Aji, A. S.; Shiratsuchi, Y.; Ding, D.; Kawahara, K.; Okada, S.; Pachal, V.; Kazakova, O.; Hibino, H.; Suenaga, K.; Ago, H. Surface-Mediated Aligned Growth of Monolayer $\mathrm{MoS}_{2}$ and In-Plane Heterostructures with Graphene on Sapphire. ACS Nano 2018, 12, 10032-10044.

(38) Zhang, K.; Bersch, B. M.; Zhang, F.; Briggs, N. C.; Subramanian, S.; Xu, K.; Chubarov, M.; Wang, K.; Lerach, J.O.; Redwing, J. M.; Fullerton-Shirey, S. K.; Terrones, M.; Robinson, J. A. Considerations for Utilizing Sodium Chloride in Epitaxial Molybdenum Disulfide. ACS Appl. Mater. Interfaces 2018, 10, 40831-40837.

(39) Zhang, X.; Meng, F.; Christianson, J. R.; Arroyo-Torres, C.; Lukowski, M. A.; Liang, D.; Schmidt, J. R.; Jin, S. Vertical Heterostructures of Layered Metal Chalcogenides by van Der Waals Epitaxy. Nano Lett. 2014, 14, 3047-3054.

(40) Zhang, X.; Zhang, F.; Wang, Y.; Schulman, D. S.; Zhang, T.; Bansal, A.; Alem, N.; Das, S.; Crespi, V. H.; Terrones, M.; Redwing, J. M. Defect-Controlled Nucleation and Orientation of $\mathrm{WSe}_{2}$ on hBN: A Route to Single-Crystal Epitaxial Monolayers. ACS Nano 2019, 13, 33413352.

(41) Zhang, X.; Choudhury, T. H.; Chubarov, M.; Xiang, Y.; Jariwala, B.; Zhang, F.; Alem, N.; Wang, G.-C.; Robinson, J. A.; Redwing, J. M. Diffusion-Controlled Epitaxy of Large Area Coalesced $\mathrm{WSe}_{2}$ Monolayers on Sapphire. Nano Lett. 2018, 18, 1049-1056.

(42) Xu, Y.; Cao, B.; Li, Z.; Cai, D.; Zhang, Y.; Ren, G.; Wang, J.; Shi, L.; Wang, C.; Xu, K. Growth Model of van Der Waals Epitaxy of Films: A Case of AlN Films on Multilayer Graphene/SiC. ACS Appl. Mater. Interfaces 2017, 9, 44001-44009. 